\title{
Dendrimer Functionalized Metal Oxide Nanoparticle mediated Self-Assembled Collagen Scaffold for Skin Regenerative Application: Function of Metal in Metal oxides
}

KJ Sreeram ( $\sim$ kjsreeram@clri.res.in )

CSIR-CLRI: Central Leather Research Institute CSIR https://orcid.org/0000-0003-1748-8754

Mohan Vedhanayagam

CSIR-CLRI: Central Leather Research Institute CSIR

Balachandran Unni Nair

CSIR-CLRI: Central Leather Research Institute CSIR

Anandasadagopan Suresh kumar

CSIR-CLRI: Central Leather Research Institute CSIR

\section{Research Article}

Keywords: Scaffold, Metal oxides, Dendrimer, Young's modulus, Skin Regeneration

Posted Date: August 3rd, 2021

DOl: https://doi.org/10.21203/rs.3.rs-761375/v1

License: (c) (i) This work is licensed under a Creative Commons Attribution 4.0 International License.

Read Full License 


\section{Abstract}

Functionalized metal oxide nanoparticles cross-linked collagen scaffolds are widely used in skin regenerative applications because of their enhanced physico-chemical and biocompatibility properties. From the safety clinical trials point of view, there are no reports that have compared the effects of functionalized metal oxide nanoparticles mediated collagen scaffolds for in-vivo skin regenerative applications. In this work, Triethoxysilane - Poly (amido amine) dendrimer generation 3 (TES-PAMAM - $\mathrm{G}_{3}$ or $\mathrm{G}_{3}$ ) functionalized spherical shape metal oxide nanoparticles (MO NPs: $\mathrm{ZnO}, \mathrm{TiO}_{2}, \mathrm{Fe}_{3} \mathrm{O}_{4}, \mathrm{CeO}_{2}$, and $\mathrm{SiO}_{2}$, Size: $12-25 \mathrm{~nm}$ ) cross-linked collagen scaffolds were prepared by using a self-assembly method. Triple helical conformation, pore size, mechanical strength and in-vitro cell viability of MO-TES-PAMAM$\mathrm{G}_{3}$ - collagen scaffolds were studied through different methods. The in-vivo skin regenerative proficiency of MO-TES-PAMAM-G ${ }_{3}$ - collagen scaffolds were analysed by implanting the scaffold on wounds in Wistar Albino rats. The results demonstrated that MO-TES-PAMAM- $\mathrm{G}_{3}$ - collagen scaffold showed superior skin regeneration properties than other scaffolds. The skin regenerative efficiency of MO NPs followed order: $\mathrm{ZnO}>\mathrm{TiO}_{2}>\mathrm{CeO}_{2}>\mathrm{SiO}_{2}>\mathrm{Fe}_{3} \mathrm{O}_{4} \mathrm{NPs}$. This result can be attributed to higher mechanical strength, cell viability and better antibacterial activity of ZnO-TES-PAMAM- $\mathrm{G}_{3}$-collagen scaffold lead to accelerate the skin regenerative properties in comparison to other metal oxide based collagen scaffolds.

\subsection{Introduction}

Fabrication of scaffold material with versatile properties including desirable mechanical strength, antibacterial, antioxidant, controlled biodegradability and biocompatibility is the forefront of research in skin regenerative application [1-5]. The collagen based scaffolds are widely used in the skin regenerative process due to their precious biological properties such as biodegradability, non-toxic, low immunogenicity and good cell adhesibility [6-9]. However, the pure form of collagen scaffold exhibits lower mechanical strength and fast biodegradation, which limits their application in-vivo studies. To conquer this issue, different strategies include using cross-linkers (physical, chemical, enzymatic), metal/metal oxide nanoparticles ( $\mathrm{Ag}, \mathrm{Au}, \mathrm{ZnO}, \mathrm{TiO}_{2}, \mathrm{SiO}_{2} \mathrm{NPs}$ ) and surface functionalized nanoparticles (metal/ metal oxide) have been used to stabilize the collagen by numerous scientists[10-15]. Among the various methods, functionalized metal oxide nanoparticle cross-linked collagen scaffold exhibited higher mechanical properties and cell viability compared to bar nanoparticles $[13,16]$. This result can be due to the smaller size combined with the larger surface area, resulting in many cross-linking points with functional molecules and protein. In addition to this, metal oxides based scaffold may have unpredictable physical (lighter and more porous), optical (tunable optical emission), magnetic (super paramagnetic), antibacterial property and antioxidant properties, which are unavailable at micro - or macroscales [13,16-21]. Recently, Huang et al have been reported that functionalized metal oxide nanoparticle mediated scaffold accelerated wound healing process[22]. The functionalized metal oxide nanoparticle forms an adhesive layer because of adsorption of protein molecules onto the nanoparticle surface. The resulting bridging layer can support high amounts of stress due to rearrangement of adsorbed proteins on the nanoparticle surface, leading to the use of scaffold in regenerative 
medicine[23]. For example, orange essential oil (EO) functionalized $\mathrm{ZnO}$ nanoparticle incorporated collagen based bioresorbable scaffold improve the skin regeneration process due to their higher antibacterial and biocompatibility[24]. Collagen integrated with polycaprolactone or polyvinyl pyrrolidone (PVP) coated titanium dioxide $\left(\mathrm{TiO}_{2}\right)$ based scaffold can be useful as skin substitute[25-26]. Mertens et al., have demonstrated that (3-aminopropyl) Triethoxy silane (APTES) functionalized $\mathrm{Fe}_{3} \mathrm{O}_{4}$ nanoparticle labelled collagen scaffold can be useful for non-invasive MR imaging in tissue regenerative applications[16]. Inspire of these reports, our group have studied an effect of various morphology of TESPAMAM- $\mathrm{G}_{1}$ dendrimer functionalized $\mathrm{ZnO}$ nanoparticle cross-linked collagen scaffold in skin regenerative application. The result obtained in that study indicated the sphere shape of $\mathrm{ZnO}$ nanoparticle exhibited a better-wound healing process than other shapes[27]. The use of PAMAM based dendrimer in that study is due to their well-defined nanostructured macromolecules with relatively low toxicity and large number of surface functional groups leading to higher cross-linking density with collagen through EDC-NHS treatment[28-29]. This cross-linking method is highly efficient, nontoxic (EDC-NHS used to activate the carboxylic groups of collagen and do not take part in cross-linking reaction) and the resultant by product can be easily removed by washing process[30].

To obtain a better understanding on the significance of metal ion and their functionality in collagen scaffold properties, we focused on the effect of TES- PAMAM- $G_{3}$ or $\mathrm{G}_{3}$ dendrimer functionalized metal oxide nanoparticles cross-linked collagen scaffold for in-vivo skin regenerative applications. To have a meaningful set of nanoparticles, we selected $\mathrm{ZnO}, \mathrm{TiO}_{2}, \mathrm{Fe}_{3} \mathrm{O}_{4}, \mathrm{CeO}_{2}$ and $\mathrm{SiO}_{2}$ as candidate oxides due to their better biological properties such as antimicrobial, antioxidant and broad application in industrial products. In this work, different metal oxide nanoparticles with spherical shapes (12-25 nm size) were prepared through the co-precipitation method. The synthesized nanoparticles were functionalized with TES-PAMAM- $\mathrm{G}_{3}$ and cross-linked with collagen via EDC- NHS coupling reaction. Prepared MO mediated collagen scaffolds were employed for in-vivo skin regenerative application as schematically showed in Fig. 1

\subsection{Experimental Section}

\subsection{Chemicals and Reagents}

Zinc acetate dihydrate $\left(\mathrm{Zn}(\mathrm{OAc})_{2} 2 \mathrm{H}_{2} \mathrm{O}\right)$, Titanium (IV) tert-butoxide $\left(\mathrm{Ti}\left[\mathrm{OC}\left(\mathrm{CH}_{3}\right)_{3}\right]_{4}\right)$, Iron (II) chloride $\left(\mathrm{FeCl}_{2}\right)$, Iron (III) chloride $\left(\mathrm{FeCl}_{3}\right)$, Cerium (III) nitrate hexahydrate $\left(\mathrm{Ce}\left(\mathrm{NO}_{3}\right)_{3} \cdot 6 \mathrm{H}_{2} \mathrm{O}\right)$, Tetraethyl orthosilicates $\left(\mathrm{Si}\left(\mathrm{OC}_{2} \mathrm{H}_{5}\right)_{4}\right)$, Sodium Oleate $\left(\mathrm{C}_{18} \mathrm{H}_{33} \mathrm{NaO}_{2}\right)$, Lithium hydroxide monohydrate $\left(\mathrm{LiOH} . \mathrm{H}_{2} \mathrm{O}\right), 2$, 5 Dihydroxybenzoic acid (DHB), Ethanol (3- amino propyl), methyl acrylate, 6-Carboxy - 2', 7'-

dichlorofluorescein diacetate (DCFH-DA), 4, 4-difluoro - 5-(4-phenyl-1,3-butadienyl)-4-bora-3a-,4a-diaza-sindacene-3-undecanoic acid (BODIPY 581/591C11), tetramethyl ammonium hydroxide (TMAH) and streptomycin sulfate salt were procured from Sigma Aldrich, USA. MTT reagent (3-(4, 5-Dimethylthiazol-2yl)-2, 5-diphenyltetrazolium bromide), Human Epidermal Keratinocytes (HaCaT) cells, Calcein AM solution were purchased from NCCS Pune, India. E.coli and S. aureus bacteria were purchased from ATCC strains. 
Cell culture equipments were procured from Nunc, Denmark. Polyethylene tray with six compartments was procured from Science Ware Pvt. Ltd India. All these chemicals and other general reagents were directly used without additional purification. In this research, Milli-Q-water $(18 \mathrm{M} \Omega . \mathrm{cm})$ was used in all the experimental analysis.

\subsection{Type I Collagen Extraction from Tendon of a Rat}

Type I collagen solution was excerpted from rat tail tendon by using salt precipitation method [31-32]. In brief, type I collagen fibers were teased out from rat tail tendons (Four month-old male Wistar Albino Rat, 3 Numbers) and placed in the ether - chloroform mixture to remove lipid content. Subsequently, tendons were immersed in $0.5 \mathrm{~N}$ acetic acid for $12 \mathrm{~h}$ at $4^{\circ} \mathrm{C}$ to swell completely leads to tendons were ground and centrifuged for 30 minutes at $16000 \mathrm{rpm}$ to obtain the supernatant solution. To this, 5\% sodium chloride $(\mathrm{NaCl})$ was added slowly until white precipitate was formed and centrifuged to collect the precipitated collagen. To concentrate crude collagen, the precipitated was dialyzed toward $0.5 \mathrm{M}$ acetic acid. To obtain a pure collagen solution, this solution was further dialyzed against $0.05 \mathrm{M}$ acetic acid to eliminate the excess salts. As a measure of hydroxyproline content, the concentration of collagen solution was determined[12].

\subsection{Synthesis of Metal Oxide Nanoparticle - Co- precipitation Method}

Metal oxide nanoparticles were synthesized by using the reported method with minor modification [3334]. For ZnO nanoparticles, Zinc acetate dihydrate was dissolved in $100 \mathrm{ml}$ ethanol/ water (80:20) mixture and heated to $90^{\circ} \mathrm{C}$ for 30 minutes. To this, the calculated amount of Lithium hydroxide solution was added drop by drop and the resulting solution was allowed to stir at the same temperature for 30 minutes. Subsequently, sodium oleate was added to the above solution and heated at $180{ }^{\circ} \mathrm{C}$ for $6 \mathrm{~h}$. The final precipitate was separated and centrifuged in the presence of hydrochloric acid - methanol mixture (1:5 ratio) and water alternatively to remove the excess sodium oleate. The final product was dried at $65^{\circ} \mathrm{C}$ in a hot air oven to obtain $\mathrm{ZnO}$ nanoparticles. A similar procedure was adopted for the preparation of $\mathrm{TiO}_{2}, \mathrm{Fe}_{3} \mathrm{O}_{4}, \mathrm{CeO}_{2}$ and $\mathrm{SiO}_{2}$ nanoparticle from the respective precursor. The $\mathrm{Fe}_{3} \mathrm{O}_{4}$ nanoparticle was prepared from a mixture of Iron (II) chloride and Iron (III) chloride precursors.

\subsection{Synthesis of TES-PAMAM - $G_{3}$ dendrimer - Divergent method}

Triethoxy silane poly (amido amine) dendrimer (TES-PAMAM-G or $_{3}$ ) was synthesized by using our previously reported procedure (Fig. S1, Supplementary file) [27].

\subsection{Surface Functionalization of Metal Oxide Nanoparticle}

Synthesized MO NPs were functionalized with TES-PAMAM-G ${ }_{3}$ dendrimer by using our previously reported procedure $[9,27]$. Both TES-PAMAM-G 3 dendrimer $(25 \mathrm{~mL}, 1.5 \mathrm{mM})$ and MO NPs, $(125 \mathrm{mg})$ were slowly added to dry methanol solution $(60 \mathrm{~mL})$ and magnetically stirred for 30 minutes at $25^{\circ} \mathrm{C}$ under 
nitrogen atmosphere. To the solution, tetramethyl ammonium hydroxide $(3.0 \mathrm{~mL}, 0.35 \mathrm{M})$ in dry methanol was added slowly for 10 minutes and the resulting reaction mixture heated to $60^{\circ} \mathrm{C}$ for $9 \mathrm{~h}$ under the same reaction condition. Afterward, the reaction mixture was slowly cooled to $25^{\circ} \mathrm{C}$ and centrifuged for 30 minutes at $15000 \mathrm{rpm}$, and the supernatant solution was discarded. The precipitated yellow-orange colored metal oxide nanoparticles were washed with methanol five times to eliminate unreacted dendrimer and then the sample was dried at $60^{\circ} \mathrm{C}$ in a hot air oven to get solid form. The obtained products were dissolved in water leads to a prepared stock solution for collagen interaction studies.

\subsection{Interaction of Collagen with MO-TES-PAMAM $-G_{3}-N P s$}

TES - PAMAM $-\mathrm{G}_{3}(1 \mu \mathrm{M})$ and MO -TES-PAMAM- $\mathrm{G}_{3}(1-20 \mu \mathrm{M})$ nanoparticles were separately added to $0.5 \mu \mathrm{M}$ of EDC-NHS reagent treated collagen solution ( $1: 1$ ratio) at $25^{\circ} \mathrm{Cto}$ perceive effect on the secondary structural (triple helical) conformation of collagen. The resulting solution was gently placed in shaking incubator for $24 \mathrm{~h}, 27^{\circ} \mathrm{C}$ at $300 \mathrm{rpm}$,

\subsection{Preparation of collagen scaffold -Self-Assembly Process}

Collagen fibril formation (Self-assembly process) was carried out according to the previously described method[12,35]. The fibril formation processes were initiated by mixing $300 \mu \mathrm{L}$ of collagen $(3 \mu \mathrm{M})$ solution with $2560 \mu \mathrm{L}$ of Phosphate buffer (50 mM PBS, NaCl ionic strength $120 \mathrm{mM}$ ) and the pH was adjusted to 7.4 using $0.5 \mathrm{~N}$ sodium hydroxide solutions. After that, both sample and blank solutions were vigorously stirred and the sample absorption $(\lambda=313 \mathrm{~nm}$ ) was measured on a UV-Vis spectrometer (Carry 100). Absorption data were continuously recorded up to 30 minutes at $37^{\circ} \mathrm{C}$. A similar procedure was adopted for EDC-NHS - collagen, TES-PAMAM-G ${ }_{3}$ - collagen, and MO - TES-PAMMA - $\mathrm{G}_{3}$ - collagen fibrils, the only difference is during the fibril formation of collagen, $30 \mu \mathrm{L}$ of EDC-NHS, TES-PAMAM $-\mathrm{G}_{3}$ and MOTES- PAMAM $-G_{3} N P_{S}$ were added to collagen. The resulting gel form of collagen samples

were transferred to polythene (12 complementary) trays with dimension of $28.5 \mathrm{~cm}$ length $(\mathrm{L}) \times 23.5 \mathrm{~cm}$ width $(\mathrm{W}) \times 7 \mathrm{~cm}$ height $(\mathrm{H})$ and each compartments having $\mathrm{L} \times \mathrm{W} \times \mathrm{H}=7 \times 8 \times 7 \mathrm{~cm}$ for scaffold preparation and air dried fully at room temperature for $168 \mathrm{~h}$. After that, the scaffold was extensively washed with water five times to remove the adhered salts.

\subsection{Characterization of Nanoparticle}

The X-ray diffraction pattern was recorded using a Miniflux 11, Rigaku diffractometer $(\lambda=0.1548$, CuKa radiation), with samples scanned along $2 \theta$ at a speed of $4^{\circ} \mathrm{min}^{-1}$ in the range of 5 to $80^{\circ}$. Analysis of amorphous and crystalline phases was carried out using standards in the JCPDS data file. HR-TEM and SAED images were obtained using a JEOL 3010 instrument. For this, synthesized nanoparticles were dispersed in methanol in an ultra-sonication bath, and two drops of it were deposited on carbon-coated copper $(\mathrm{Cu})$ grid and analyzed under an accelerating voltage of $300 \mathrm{kV}$. Image $\mathrm{J}$ software was used to calculate the particle size from obtained HR-TEM image. The molecular mass of the TES-PAMAM-G 3 
dendrimer was confirmed by using a Bruker MALDI-TOF (Matrix-assisted laser desorption ionization- time of flight and equipped with a pulsed nitrogen laser $(337 \mathrm{~nm})$, operating in positive ion reflector mode, using $19 \mathrm{kV}$ acceleration voltage and 2,5-dihydroxybenzoic acid in $0.1 \mathrm{M}$ trifluoro acetic acid solution was used as a matrix (Fig. 2, Supplementary file). FT-IR spectrum (JASCO spectrometer) of the nanoparticles was recorded in the range $400-4000 \mathrm{~cm}^{-1}$ and $600-4000 \mathrm{~cm}^{-1}$ (ATR mode) at $4 \mathrm{~cm}^{-1}$ resolution, averaged over 100 scans for powder and film samples respectively. A transparent pellet was prepared with potassium bromide in the ratio- sample: $\operatorname{KBr}(2: 98)$ for the powder samples, and the final spectrum was obtained after subtracting the $\mathrm{KBr}$ background spectra. In the case of the film sample, the air was used as a background. Differential scanning calorimetry (DSC) was used to assess the thermal stability of scaffolds (Q200, TA instruments). In a nitrogen atmosphere, collagen -based scaffold ( $\sim 5 \mathrm{mg}$ ) was uniformly mounted in aluminium pans with lids and scanned over a temperature range of $30-180^{\circ} \mathrm{C}$ at a heating rate of $10^{\circ} \mathrm{C}$ per minute. The denaturation temperature $(\mathrm{Td})$ was estimated at the transition peaks midpoint. For each sample, DSC measurements were performed five times and Td values were measured as the average of five replicates.

\subsection{Circular Dichroism spectroscopy - Collagen- Nanoparticle Interaction}

The effect of TES-PAMAM- $\mathrm{G}_{3}$ and its functionalized MO nanoparticle on the triple helical structure of collagen was investigated through circular dichroism spectro polarimeter (JASCO-J.815). In the nitrogen atmosphere, CD spectra were recorded for every $0.2 \mathrm{~nm}$ by averaging five scans in the far UV region (190$260 \mathrm{~nm}$ ) with a $1 \mathrm{~nm}$ bandwidth and a scan speed of $100 \mathrm{~nm} \mathrm{~min}{ }^{-1}$. The results of the CD spectra were expressed in molar ellipticity. The ration of positive to negative pinnacle statures (Rpn) can be used as a measure of triple - helix content, with values near 0.12 indicating a completely triple helical structure.

\subsection{Characterization of Collagen-Nanoparticle Scaffolds}

Tensile strength analysis was performed on collagen scaffolds using a Universal testing machine (INSTRON model 1405$)$ at $230 \mathrm{C}$ and $50 \%$ relative humidity. The rectangular shaped $(1.5 \times 7 \mathrm{~cm}$, thickness 0.03-0.09) scaffolds were tensile tested at a crosshead speed of $5 \mathrm{~mm} \mathrm{~min}^{-1}$ before the collagen scaffold ruptured. The linear portion of tensile stress-tensile strain curve was used to calculate the Young's modulus of collagen scaffold. The tensile strength, elongation at break and Young's modulus of scaffolds were measured in triplicate. High-resolution scanning electron microscopy was used to investigate the morphology of collagen scaffold (HR-SEM, Quanta $200 \mathrm{FEG}$ ). Before placing the sample on the stub, scaffolds were sputter -coated with gold to prevent contamination. Image $\mathrm{J}$ software was used to examine the collagen scaffold pore size, fiber diameter and D-periodicity.

\subsection{In-Vitro Bio-degradation of MO-TES-PAMAM-G ${ }_{3}$ - Collagen Scaffold}

Biodegradation of collagen, TES-PAMAM- $\mathrm{G}_{3}$ - collagen, and MOs-TES-PAMAM- $\mathrm{G}_{3}$ - collagen scaffolds was investigated by immersing correctly weighed $(5 \mathrm{mg})$ scaffolds of equivalent size in $3000 \mu \mathrm{L}$ of PBS (pH 7.4 ) at $37^{\circ} \mathrm{C}$ for up to 45 days. The biodegradation rate of prepared scaffolds was measured as a 
percentage of weight loss over time compared to a fully degraded scaffold of similar composition and weight. The percentage of degradation was evaluated by the following Eq. (1)

Degradaton $(\backslash \%)=\left[\left(\mathrm{W}_{\mathrm{i}}-\mathrm{W}_{\mathrm{t}}\right) / \mathrm{W}_{\mathrm{i}}\right] \mathrm{X} 100(1)$

where the sample weight before immersion in PBS is $W_{i}$, and the sample final weight after freeze drying is $\mathrm{W}_{\mathrm{t}}$. Three samples were analysed in parallel, and the average outcome was plotted.

\subsection{Swelling Degree of MOs-TES-PAMAM-G ${ }_{3}$-Collagen Scaffold}

The gravimetric approach was used to assess the swelling degree (Sd) or water absorption of collagen based scaffolds. The swelling ration, as defined by Eq. (2), was used to assess the Sd.

$$
\text { Wateruptake }(\backslash \%)=\left[\left(\mathrm{W}_{\mathrm{s}}-\mathrm{W}_{\mathrm{d}}\right) / \mathrm{W}_{\mathrm{d}}\right] \mathrm{X} 100(2)
$$

Where $W_{d}$ is the initial weight of dry collagen, and $W_{s}$ is the weight of swollen collagen at equilibrium. Every 5 hours, the dried scaffolds were weighed and immersed in ultrapure water until they reached a swelling equilibrium, and readings were taken. After that, the scaffolds were weighed again after being impaired with filter paper to extract excess water from their surface. Each value was calculated as the mean of five separate measurements and expressed as a standard deviation (SD).

\subsection{Evaluation of Cross linking degree in Collagen Scaffold}

The percentage of cross-linked carboxylic group in collagen- dendrimer composite was calculated through reported methods[29]. The reaction of collagen with the acylating -acetic acid ester (HAc-NHS) in the ratio of $(1: 3)$ congested the unrestricted amine groups in collagen, and the reaction mixture was stirred for $5 \mathrm{~h}$ at $25^{\circ} \mathrm{C}$. This amine group congested collagen samples were added to a solution of EDC and $\mathrm{NHS}$ reagent, and the $\mathrm{pH}$ of the resulting solution was maintained at 5.5.Subsequently, $0.2 \mathrm{M}$ of $\mathrm{NaH}_{2} \mathrm{PO}_{4}$ buffer was slowly added to the above solution and centrifuged at $15000 \mathrm{rpm}$ for 45 minutes to eliminate the excess NHS, and then $1 \mathrm{~mL}$ of $0.1 \mathrm{M} \mathrm{Na}_{2} \mathrm{HPO}_{4}$ buffer $(\mathrm{pH} 9.1)$ was added and stirred for $2 \mathrm{~h}$. The quantity of NHS released in the sample was determined through absorbance at $260 \mathrm{~nm}$ by considering $\varepsilon=9700 \mathrm{M}^{-1} \mathrm{~cm}^{-1}$.

\subsection{Bio-Compatibility}

The biocompatibility of collagen-based scaffolds was analysed by using MTT assay[36]. Briefly, the scaffolds viz., collagen, TES-PAMAM-G ${ }_{3}$-collagen, MO-TES -PAMAM G ${ }_{3}$-collagen (MO: ZnO, $\mathrm{TiO}_{2}, \mathrm{Fe}_{3} \mathrm{O}_{4}$, $\mathrm{CeO}_{2}$ and $\mathrm{SiO}_{2} \mathrm{NPs}$ ) were placed in the cell culture plate, and UV sterilized for 3 hours. After UV sterilization, $3 \times 10^{4}$ human immortalized keratinocyte ( $\mathrm{HaCaT}$ ) cells were seeded onto the 48 well tissue culture plates comprising scaffolds and allowed to grow in $5 \% \mathrm{CO}_{2}$. After 24 hours of incubation, the culture medium was separated, and the cells were treated with $0.5 \mathrm{mgmL}^{-1}$ of MTT reagent in PBS and incubated in the dark at $37^{\circ} \mathrm{C}$ for $4 \mathrm{~h}$. The purple-colored formazan crystals produced were solubilized 
with dimethyl sulphoxide (DMSO) after incubation and the absorbance was measured at $570 \mathrm{~nm}$ in a BioRed ELISA plate reader. The following Eq. (3) was used to measure the percentage of viable cells.

$$
\backslash \% \text { CellViability }=\frac{\text { Absorbanceat570nmintreatedcells }}{\text { Absorbanceat570nminthecontrolcells }} \times 100(3)
$$

\subsection{Wound Healing Studies}

An in-vivo animal model research was undertaken with approval from the institutional animal ethical committee (Approval No IAEC No. 09/2017(a)) to assess the effectiveness of MO-TES-PAMAM-G $3^{-}$ collagen scaffold as a wound cover material. All animal experiments were executed according to the institutional ethical clearance guidelines. For this study, male Albino (Wistar strain) weighing $145-165 \mathrm{~g}$ were used. Animals were randomly divided into eight groups, each with four animals. Group I (controlwound enclosed with cotton soaked in phosphate buffered saline), Group II (wound enclosed with pure collagen scaffold), Group III (wound enclosed with scaffold of TES-PAMAM $-\mathrm{G}_{3}$ - collagen), Group-IV (wound enclosed with scaffold of ZnO-TES-PAMAM- $\mathrm{G}_{3}$ - collagen), Group-V (wound enclosed with scaffold of $\mathrm{TiO}_{2}$-TES-PAMAM $-\mathrm{G}_{3}$ - collagen), Group-VI (wound enclosed with scaffold of $\mathrm{Fe}_{3} \mathrm{O}_{4}$-TESPAMAM $-\mathrm{G}_{3}$-collagen), Group-VII (wound enclosed with scaffold of $\mathrm{CeO}_{2}-$ TES-PAMAM $-\mathrm{G}_{3}-\mathrm{Collagen}$ ) and Group-VIII (wound enclosed with scaffold of $\mathrm{SiO}_{2}$ - TES-PAMAM $-\mathrm{G}_{3}$ - collagen). With the aid of scissor and a surgical needle, a $4 \mathrm{~cm}^{2}\left(2 \times 2 \mathrm{~cm}^{2}\right)$ incision was made on the dorsal part of all the rats, and the wound region was immediately sterilised with surgical spirit. Animals were dressed and gauze was used to close the dressing scaffold. Each alternate day, all of the rats had their dressings changed. At every 7th day cycle, wound contraction was calculated as a percentage reduction in wound size and photographed. The region of the wound was measured using image $\mathrm{J}$ software, and the size of the wound was monitored on a regular basis by tracing the boundary.

The wound healing percentage was estimated by using Eq. (4)

$$
\text { Woundhealing }(\backslash \%)=\frac{\text { (Originalwoundareaonday0 }- \text { Woundareaondayn })}{\text { Originalwoundareaonday0 }} \mathrm{x} 100(4)
$$

\subsection{Histopathology and Masson's Trichrome Analysis}

On the 7th, 14th, and 21 st post-operative days, the healed wound region was excised along with scar tissue from various groups and fixed with a $12 \%$ formalin solution for $24 \mathrm{~h}$ at room temperature to understand the healing process. Different grades of alcohol and xylene were used to treat the tissues. The tissue was then embedded in paraffin wax and cut into $5 \mu \mathrm{m}$ thick sections. Hematoxylin-Eosin (H\&E) and Masson's trichrome reagent were used to stain tissue parts, which were then examined under an optical microscope (10X, Zeiss Axioscope microscope).

\subsection{Metal ion quantification by ICP-OES Analysis}


ICP-OES was used to test the quantification of metal oxide nanoparticles in wound-healed skin samples (Perkin Elmer Optima 5300DV). The healed skin samples having an area of $4 \mathrm{~cm}^{2}$ were digested in conc. $\mathrm{HNO}_{3}$ and $\mathrm{HCl}\left(7: 3\right.$ ratio) mixture in a hot air oven at $65^{\circ} \mathrm{C}$ for 15 minutes. The reagent blank used in the analysis was a mixture of $\mathrm{HNO} 3$ and $\mathrm{HCl}$ solution, and a calibration plot was generated by examining high purity ICP standards. The results were recorded and processed using Win Lab 32 software.

\subsection{Statistical Evaluation}

The experimental data from all the studies were repetitive five times and indicated as means \pm standard deviation (SD). Graph pad prism software versions 5.00 (San Diego California USA, trial version) was used for statistical analysis. Statistical significance was set to a p-value $\leq 0.05$.

\subsection{Results And Discussion}

\subsection{XRD-Crystal Structure of Metal Oxide Nanoparticle}

X-ray diffraction pattern of synthesized metal oxide nanoparticles such as $\mathrm{ZnO}, \mathrm{TiO}_{2}, \mathrm{Fe}_{3} \mathrm{O}_{4}, \mathrm{CeO}_{2}$, and $\mathrm{SiO}_{2}$ are showed in Fig. 2. All the samples display sharp crystalline peaks except $\mathrm{SiO}_{2}$ nanoparticle, and it

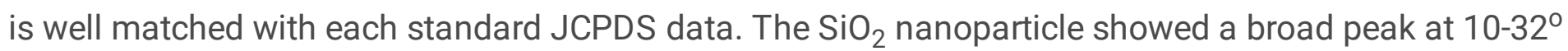
suggesting that the synthesized nanomaterial exhibits an amorphous nature[37]. As seen in figure, the width of peak expansions in all metal oxide nanoparticles, a clear indication that the particle size of nanoparticle decreases[38-39]. The crystallite size of nanoparticles was estimated by using the DebyeScherrer formula. The crystal structure, phase group, lattice constants, and crystallite size are presented in Table.1, Supplementary file. The results reveal that all the synthesized metal oxide nanoparticles exhibit a crystallite size of about $\mathrm{ZnO}(4 \mathrm{~nm}), \mathrm{TiO}_{2}(7 \mathrm{~nm}), \mathrm{Fe}_{3} \mathrm{O}_{4}(11 \mathrm{~nm}), \mathrm{CeO}_{2}(9 \mathrm{~nm})$, and $\mathrm{SiO}_{2}(7 \mathrm{~nm})$. Absence of impurity peaks in the XRD spectrum, implying that prepared nanoparticles exhibit high purity.

\subsection{HR-TEM- Morphology of Metal Oxide Nanoparticles}

The morphology of different metal oxide nanoparticles was assessed through HR-TEM analysis. Figure 3 shows that the synthesized $\mathrm{MO}$ nanoparticles $\left(\mathrm{ZnO}, \mathrm{TiO}_{2}, \mathrm{Fe}_{3} \mathrm{O}_{4}, \mathrm{CeO}_{2}\right.$, and $\left.\mathrm{SiO}_{2}\right)$ exhibit spherical morphology with uniform size through the area. The diameter of $\mathrm{ZnO}, \mathrm{TiO}_{2}, \mathrm{Fe}_{3} \mathrm{O}_{4}, \mathrm{CeO}_{2}$, and $\mathrm{SiO}_{2}$ nanoparticles were in the range of 3-5 nm, 3-7 nm, 5-12 nm, 4-9 nm and 7-14 nm respectively. As seen in figure, the SAED pattern reveals that synthesized nanoparticle exhibit polycrystalline nature except for $\mathrm{SiO}_{2}$ nanoparticles, which exhibits an amorphous character.

\subsection{FTIR- Functionalization of TES-PAMAM-G ${ }_{3}$ dendrimer on Metal Oxide Nanoparticles}

. Metal oxide nanoparticles were evaluated using FT-IR spectroscopic techniques to ensure the functionalization of the TES-PAMAM- $\mathrm{G}_{3}$ dendrimer. Figure 4 shows the FTIR spectrum of the TES- 
PAMAM $-G_{3}$ dendrimer, metal oxide, and TES-PAMAM $-G_{3}$ dendrimer functionalized metal oxide. The N-H stretching vibration of primary amines was allocated to bands at $3389 \mathrm{~cm}^{-1}$ and $3018 \mathrm{~cm}^{-1}$ for TESPAMAM- $\mathrm{G}_{3}$ dendrimer. The asymmetric and symmetric stretching vibration of the $-\mathrm{CH}_{2}$ group were assigned to the bands observed at $2972 \mathrm{~cm}^{-1}$ and $2840 \mathrm{~cm}^{-1}$, respectively. The stretching vibration of the $-\mathrm{OCH}_{2} \mathrm{CH}_{3}$ group (merged with the $-\mathrm{CH}_{2}$ group) was characterised by a very weak band that appeared at $2815 \mathrm{~cm}^{-1}$. In the TES-PAMAM-G ${ }_{3}$ dendrimer, the prominent bands observed at 1644, 1554, and 1294 $\mathrm{cm}^{-1}$ correspond to $\mathrm{C}=\mathrm{O}$ stretching, $\mathrm{N}-\mathrm{H}$ bending coupled with $\mathrm{C}-\mathrm{N}$ stretching, and a combination of $\mathrm{C}-\mathrm{N}$ stretching with $\mathrm{N}-\mathrm{H}$ in plane bending vibration from amide group linkage. The band that appeared at $1465 \mathrm{~cm}^{-1}$ corresponded to the dendrimer $-\mathrm{CH}_{2}$ scissoring vibration. The band related to the Si-O stretching vibration in the siloxane group was appeared at $1174 \mathrm{~cm}^{-1}$. The $-\mathrm{C}-0$ stretching frequency of the carbonyl group in PAMAM-G ${ }_{3}$ dendrimer was allocated to the band at $1041 \mathrm{~cm}^{-1}$.

A band that appeared at $3400-3500 \mathrm{~cm}^{-1}$ for pure metal oxide nanoparticles was a standard $-\mathrm{OH}$ group band, as observed in all cases. Figure 4 shows a broad absorption band at $492 \mathrm{~cm}^{-1}$ that corresponds to nanoparticle $\mathrm{Zn}-\mathrm{O}$ stretching vibrations. The band seen at $621,594,549$, and $412 \mathrm{~cm}^{-1}$ in $\mathrm{TiO}_{2}$ corresponds to Ti-O stretching vibrations. The bands appeared at 556 and $423 \mathrm{~cm}^{-1}$ for $\mathrm{Fe}_{3} \mathrm{O}_{4}$ nanoparticles, which corresponds to $\mathrm{Fe}-\mathrm{O}$ stretching vibration of iron oxide nanoparticles. $\mathrm{CeO}_{2}$, which is the standard band for the $\mathrm{Ce}-\mathrm{O}$ stretching vibration, is responsible for the absorption bands at 848 and $521 \mathrm{~cm}^{-1}$. The Si-O-Si stretching vibration of $\mathrm{SiO}_{2}$ nanoparticles was indicated by the band at $1100 \mathrm{~cm}^{-1}$.

The FTIR spectrum of TES-PAMAM-G ${ }_{3}$ functionalized metal oxide nanoparticles revealed both TESPAMAM $-G_{3}$ dendrimer and metal oxide bands, along with some deviations. As can be seen in the figure, the metal oxides bands were shifted to lower wavenumber as well as intense bands observed at 2849 and $2936 \mathrm{~cm}^{-1}$. Furthermore, no band was detected at $2810-2825 \mathrm{~cm}^{-1}$, which is typical of the- $\mathrm{O}-\mathrm{CH}_{2}-\mathrm{CH}_{3}$ group. The FTIR spectrum revealed that the TES-PAMAM- $\mathrm{G}_{3}$ dendrimer was present on the surface of metal oxide nanoparticles through non-covalent interactions.

\subsection{DLS-Hydrodynamic Size of MO-TES-PAMAM-G ${ }_{3} N P S$}

Hydrodynamic diameter, polydispersity index, and colloidal stability (measured in terms of zeta potential) of TES-PAMAM- $\mathrm{G}_{3}$ dendrimer and its functionalized metal oxide nanoparticles were analyzed and results are presented in Table 2, Supplementary file. The observed results indicate that functionalized metal oxide nanoparticles exhibit a hydrodynamic diameter of $14,17,25,20$, and $12-23 \mathrm{~nm}$ for $\mathrm{ZnO}, \mathrm{TiO}_{2}$, $\mathrm{Fe}_{3} \mathrm{O}_{4}, \mathrm{CeO}_{2}$, and $\mathrm{SiO}_{2}$ respectively. These results clearly indicated that the hydrodynamic diameter of TES-PAMAM- $\mathrm{G}_{3}$ functionalized metal oxide nanoparticles were higher than pure metal oxide nanoparticles owing to existence of dendrimer molecules on metal oxide nanoparticle surface. The observed difference in size of metal oxide nanoparticle by XRD, TEM and DLS analysis due to difference principles employed in each techniques during the measurement of nanoparticle size. The DLS analysis is based on the Brownian motion of the nanoparticle in a suspension that provide mean hydrodynamic 
diameter, which is typically larger than XRD and TEM techniques because it contains a few solvent layers on surface. In general, colloidal stability of nanoparticle has been playing an important role in protein nanoparticle interaction for various biomedical applications. TES-PAMAM $-\mathrm{G}_{3}$ dendrimer functionalized metal oxide nanoparticles exhibited zeta potential in the rage of +12 to $+30 \mathrm{mV}$ and polydispersity index (PDI) 0.3, and these results indicate moderate to high colloidal stability. Both FT-IR and zeta potential measurements clearly reveal that TES-PAMAM $-G_{3}$ dendrimer was present on metal oxide nanoparticles, providing them with better colloidal stability.

\subsection{CD-Structural Changes of Collagen in presence of MO- TES-PAMAM-G 3 NPs}

Collagen triple helical structure is critical for preserving the mechanical strength and cell viability of the protein in biomedical applications[40]. The effects of TES-PAMAM- $G_{3}$ and MO-TES-PAMAM- $G_{3}$ on the triple helical structure of collagen were studied using a CD spectrum (S 2, Supplementary file). Collagen has a positive peak at $220 \mathrm{~nm}\left(\mathrm{n} \rightarrow \pi^{*}\right)$ and a negative peak at $198 \mathrm{~nm}\left(\pi \rightarrow \pi^{*}\right)$ in the CD spectrum, with a cross-over at $210 \mathrm{~nm}$ in the far UV-region. Collagen CD spectrum was found to be identical to previously recorded spectra[41]. CD spectra of collagen with varying concentrations $(1-20 \mu \mathrm{M})$ of TES-PAMAM $-\mathrm{G}_{3}$ and MO-TES-PAMAM $-G_{3}$ were akin to a spectrum of collagen. These observations indicate that the addition of MO-TES-PAMAM- $\mathrm{G}_{3}$-NPs to collagen solution did not change the triple helical structure of collagen significantly up to $20 \mu \mathrm{M}$ concentration due to presence of TES-PAMAM - $\mathrm{G}_{3}$ dendrimer on the metal oxide nanoparticle surface. The pure collagen solution exhibited an Rpn value of 0.12 . The Rpn for collagen treated with various concentrations of TES-PAMAM- $G_{3}$ and MO-TES-PAMAM- $G_{3}$ nanoparticles were in the range of $0.1 \pm 0.03$ (Data not showed). The $C D$ spectral alteration with minor variation in Rpn ratio, in the presence of TES-PAMAM $-G_{3}$ and MO-TES-PAMAM $-G_{3}$ reveal that triple helical structure of collagen is preserved. It has been reported that during the protein -nanoparticle interactions, the conformation changes of protein depending on the size and shape of the nanoparticle[42-43]. In addition, the surface curvature nanoparticle has substantial influence on adsorption of protein molecules, which can cause various conformational changes structure adsorbed to flat surface of the same material[44]. In this study, sphere shape of dendrimer functionalized metal oxide nanoparticle upon interaction with collagen does not change its triple helical structure due to smaller size (12-25 nm) with no surface curvature leads to retain more native like structure.

\subsection{Self-Assembly Process-Rate of Fibril Formation}

The effect of MO-TES-PAMAM- $\mathrm{G}_{3}$-NPs on the collagen self-assembly process can be analysed by observing the turbidity of the samples. The self-assembly processes of collagen in the presence of EDC$\mathrm{NHS}$, TES-PAMAM- $\mathrm{G}_{3}$, and TES-PAMAM $-\mathrm{G}_{3}$ functionalized metal oxide nanoparticles ( $\mathrm{MO}: \mathrm{ZnO}, \mathrm{TiO}_{2}$, $\mathrm{Fe}_{3} \mathrm{O}_{4}, \mathrm{CeO}_{2}$, and $\mathrm{SiO}_{2}$ ) are showed in Fig. S3, Supplementary file The collagen displayed a typical selfassembly or turbidity curve, similar to a sigmoidal profile, as seen in the figure, which is thought to have resulted from the three different stages of the fibrillogenesis process, namely nucleation, growth, and 
gelation[35, 45]. The pseudo kinetic parameters lag ( $\mathrm{t}$ ) (nucleation lag time) and slope (growth rate) were extracted from the absorbance profile by fitting the experiment results. The presence of TES-PAMAM $-\mathrm{G}_{3}$ and TES-PAMAM $-G_{3}$ functionalized $\mathrm{ZnO}$ nanoparticle reduced the lag $(\mathrm{t})$ value gradually with increasing concentration of nanoparticle, indicating that functionalized metal oxide nanoparticles accelerated the nucleation process of collagen. Experiments with additions of the other metal oxides such as $\mathrm{TiO}_{2}, \mathrm{Fe}_{3} \mathrm{O}_{4}$, $\mathrm{CeO}_{2}$, and $\mathrm{SiO}_{2}$ nanoparticles to collagen also followed the same trend in lag ( $\mathrm{t}$ ) values (Table 3, Supplementary file). The self-assembly of collagen is accelerated by dendrimer functionalized metal oxide nanoparticles in the following order: $\mathrm{SiO}_{2}>\mathrm{ZnO}>\mathrm{TiO}_{2}>\mathrm{Fe}_{3} \mathrm{O}_{4}>\mathrm{CeO}_{2} \mathrm{NPs}$. This observation clearly indicated that $\mathrm{SiO}_{2}$ - TES-PAMAM $-\mathrm{G}_{3}$ nanoparticle accelerate the collagen self-assembly process much more quickly than other metal oxides nanoparticles. This result can be explained by the smaller size (12$23 \mathrm{~nm}$ ) of $\mathrm{SiO}_{2}$ nanoparticles combined with their higher surface area, which has a high adsorption potential, resulting in a high local concentration of collagen on the nanoparticles surface. The high local collagen concentration leads to a shortened lag-time for collagen self-assembly into fibrils. These processes can be used to speed up wound healing applications[46].

\subsection{HRSEM - Surface structure of Collagen-based Scaffolds}

The surface structure of collagen, TES-PAMAM $-G_{3}$-collagen and MO-TES-PAMAM- $G_{3}-$ collagen scaffolds were observed by scanning electron microscopy. As seen in Fig. 5, collagen scaffold displayed porous surface with interconnected pore structures of $0.25-0.75 \mu \mathrm{m}$ (fiber diameter $0.56-0.40 \mu \mathrm{m}$ ). The collagen scaffolds were standardised after cross-linking by EDC/NHS with interconnected pore structures of $0.28-0.66 \mu \mathrm{m}$ (fiber diameter $0.15-0.82 \mu \mathrm{m}$ ). The TES-PAMAM- $\mathrm{G}_{3}$ dendrimer cross-linked collagen scaffolds had a porous structure $(0.20-0.47 \mu \mathrm{m})$ with very thin fibre diameter $(0.118-0.58 \mu \mathrm{m})$ and were denser than collagen due to chemical cross-linking between collagen and dendrimer molecules. The pore size and fiber diameter of TES-PAMAM- $\mathrm{G}_{3}$ functionalized metal oxide nanoparticle cross-linked collagen scaffolds were: $\mathrm{ZnO}(0.169-0.950 \mu \mathrm{m}$ and $0.125-0.418 \mu \mathrm{m}), \mathrm{TiO}_{2}(0.150-0.379 \mu \mathrm{m}$ and $0.130-0.581$ $\mu \mathrm{m}), \mathrm{Fe}_{3} \mathrm{O}_{4}(0.147-0.431 \mu \mathrm{m}$ and $0.110-0.458 \mu \mathrm{m}), \mathrm{CeO}_{2}(0.257-0.425 \mu \mathrm{m}$ and $0.135-0.484 \mu \mathrm{m})$ and $\mathrm{SiO}_{2}(0.230-0.333 \mu \mathrm{m}$ and $0.188-0.475 \mu \mathrm{m})$. From the corresponding HR-SEM image, it is clear that the collagen fibers are randomly formed as an interwoven network structure and the average diameter of fiber and pore size in the presence of metal oxide nanoparticles is lesser than collagen fiber. Among the metal oxide mediated collagen scaffolds, the $\mathrm{ZnO}$ exhibited larger pore size than $\mathrm{TiO}_{2}, \mathrm{Fe}_{3} \mathrm{O}_{4} \mathrm{CeO}_{2}, \mathrm{SiO}_{2}$ nanoparticle. This observation can be interpreted by a change in the crystallize size of the nanoparticle, the smaller crystallite size of nanoparticle strongly binded between the collagen fibers leading to an increase in the fiber diameter and also preventing them from separating to form a large porous structure. This significant differences in the underlying surface structure of MO-TES-PAMAM-G ${ }_{3}$-collagen scaffolds when compared to collagen, possibly increases the mechanical properties of the scaffold.

\subsection{FT-IR- Chemical Interaction between Collagen and MO- TES-PAMAM-G 3}


FTIR spectroscopy was used to examine the interaction of collagen with TES-PAMAM- $\mathrm{G}_{3}$ dendrimer functionalized metal oxide nanoparticles, and the findings are shown in S4, Supplementary file. The obtained result shows that the bands observed at 1658,1564, and $1245 \mathrm{~cm}^{-1}$ correspond to collagen amides I, II, and III. The $-\mathrm{OH}$ stretching and bending vibration of collagen is responsible for the bands at 3420 and $1418 \mathrm{~cm}^{-1}$. The band that appeared at $1020 \mathrm{~cm}^{-1}$ is the $-\mathrm{C}-\mathrm{O}$ stretching frequency of collagen characteristic band. Similar bands were found in the cross-linked collagen scaffolds TES-PAMAM- $\mathrm{G}_{3}$ and MO-TES-PAMAM- $G_{3}$. In addition, several new bands were observed in the functionalized MO-collagen scaffolds FTIR spectrum. The band that appeared at $1168 \mathrm{~cm}^{-1}$ in the TES-PAMAM-G ${ }_{3}$-collagen and MOTES-PAMAM- $\mathrm{G}_{3}$-collagen scaffolds is attributed to dendrimer Si-O stretching frequency. Changes in the carbonyl region of the TES-PAMAN-G ${ }_{3}$ MO-TES-PAMAM-G ${ }_{3}$ NPs cross-linked collagen scaffold were observed in both cases, influencing the relative ratio between amides and carboxyl group. In the collagenTES-PAMAM-G ${ }_{3} /$ MO-TES-PAMAM-G ${ }_{3}$-NPs, there was a relative decrease in the intensity of carboxylateassociated bands (protonated carboxylic acids at $1720 \mathrm{~cm}^{-1}$ ) and a relative increase in the amide bands (e.g., amide I at $1680 \mathrm{~cm}^{-1}$ ). These results clearly indicated that both TES-PAMAM-G ${ }_{3}$ and MO-TESPAMAM- $G_{3}$ nanoparticles were effectively cross-linked with collagen via amide bond linkage leads to an insignificant impact on the triple helical conformation of collagen.

\subsection{DSC-Thermal Stability of Collagen - MO-TES-PAMAM-G ${ }_{3}$ Scaffold}

Thermal stability of collagen, EDC-NHS -collagen, TES-PAMAM- ${ }_{3}-$ collagen, and MOs -TES-PAMAM-G ${ }_{3}{ }^{-}$ collagen scaffolds were assessed by DSC analysis and observed results are showed in Fig. 6a. The pure collagen scaffold showed a denaturation temperature of around $98.40 \pm 0.5^{\circ} \mathrm{C}$. This observation was in line with previous collagen scaffold studies[47]. The denaturation temperature of collagen was slightly shifted to higher temperature 102.12 and $107.56^{\circ} \mathrm{C}$ for EDC-NHS and TES-PAMAM- ${ }_{3}$ cross-linked collagen scaffolds. Interestingly, MO- TES-PAMAM-G $\mathrm{G}_{3}$ nanoparticle cross-linked collagen scaffold showed substantially higher denaturation temperature than collagen, EDC-NHS, and TES-PAMAM-G ${ }_{3}$ cross-linked scaffolds. ZnO-TES-PAMAM- $\mathrm{G}_{3}$-collagen, $\mathrm{TiO}_{2}$-TES- PAMAM- $\mathrm{G}_{3}$-collagen, $\mathrm{Fe}_{3} \mathrm{O}_{4}$-TES-PAMAM- $\mathrm{G}_{3}{ }^{-}$ collagen, $\mathrm{CeO}_{2}$-TES-PAMAM- $\mathrm{G}_{3}$-collagen and $\mathrm{SiO}_{2}$-TES- PAMAM- $\mathrm{G}_{3}$-collagen exhibited denaturation temperature of $120.08 \pm 0.3,117.73 \pm 0.8,116.50 \pm 0.4,118.55 \pm 0.1$ and $113.34 \pm 0.9^{\circ} \mathrm{C}$ respectively. Compared to our previously reported ZnO-TES-PAMAM- $\mathrm{G}_{1}$ - collagen scaffold, ZnO-TES-PAMAM-G ${ }_{3}$ scaffold has 28 times higher denaturation temperature[27]. This observation suggested that ZnO- TESPAMAM- $G_{3}$ nanoparticle-mediated collagen scaffold had higher denaturation temperature leading to higher order stability than other scaffolds.

\subsection{Mechanical Properties}

The mechanical strength of the collagen based scaffold was assessed using a tensile strength test and the results are shown in Fig. 6b. As can be seen in the figure, all collagen-based scaffolds exhibited a 
typical stress-strain curve. The pure collagen scaffold exhibited higher elongation than other scaffolds, which implies that the collagen scaffold possesses higher flexibility than other scaffolds. In the case of metal oxide nanoparticle mediated collagen scaffold a distinctive yield point is observed when compared to collagen, EDC-NHS, and TES-PAMAM - $\mathrm{G}_{3}$ cross-linked collagen scaffold indicating a transition from an elastomeric to a tough plastic nature. The linear component of the stress-strain curves was used to measure the Young's modulus. The tensile strength, percentage of strain, and Young's modulus of scaffolds are presented in Table 4, Supplementary file. As seen in the table, the tensile strength, Young's modulus and strain (\%) were $0.76 \pm 0.4 \mathrm{MPa}, 7.71 \pm 0.3 \mathrm{MPa}$ and $8.36 \%$ respectively for collagen in comparison to the EDC-NHS- collagen scaffold which had tensile strength of $2.21 \pm 0.1 \mathrm{MPa}$, Young's modulus of $90 \pm 0.8 \mathrm{MPa}$ and strain of $1.88 \%$ respectively. The TES-PAMAM- $\mathrm{G}_{3}$ collagen scaffold showed tensile strength $10.93 \pm 0.7 \mathrm{MPa}$, Young's modulus of $181 \pm 0.5 \mathrm{MPa}$ and strain of $6.67 \%$. In the case of TES-PAMAM- $\mathrm{G}_{3}$ functionalized $\mathrm{ZnO}, \mathrm{TiO}_{2}, \mathrm{Fe}_{3} \mathrm{O}_{4}, \mathrm{CeO}_{2}$ and $\mathrm{SiO}_{2}$ nanoparticle- collagen the tensile strength was $11.56 \pm 0.9 \mathrm{MPa}, 5.54 \pm 0.5 \mathrm{MPa}, 5.68 \pm 0.2 \mathrm{MPa}, 2.84 \pm 0.9 \mathrm{MPa}, 5.51 \pm 0.6 \mathrm{MPa}$ and Young's modulus of $273.14 \pm 0.2 \mathrm{MPa}, 135.30 \pm 1.0 \mathrm{MPa}, 100.01 \pm 0.3 \mathrm{MPa}, 76.49 \pm 0.5 \mathrm{MPa}, 236 \pm 0.2$ MPa and strain of $5.36 \%, 4.58 \%, 5.31 \%, 3.65 \%, 1.69 \%$ respectively. The Young's modulus of MOs-TESPAMAM- $\mathrm{G}_{3}$ NPs cross-linked collagen scaffold followed the order: $\mathrm{ZnO}>\mathrm{SiO}_{2}>\mathrm{TiO}_{2}>\mathrm{Fe}_{3} \mathrm{O}_{4}>\mathrm{CeO}_{2}$. This result suggested $\mathrm{ZnO}-\mathrm{TES}-\mathrm{PAMAM}-\mathrm{G}_{3}$ mediated collagen scaffold exhibit 35 fold higher Young's modulus than pure collagen scaffold. Compared to $\mathrm{CeO}_{2}$ - TES-PAMAM- $\mathrm{G}_{3}$ mediated collagen scaffold, ZnO- TES-PAMAM- $G_{3}$ mediated collagen scaffold showed 3.5 fold higher Young's modulus $(p \leq 0.05)$. In addition to this, $\mathrm{ZnO}$ nanoparticle mediated collagen scaffold indicate higher elastic nature than other metal oxide mediated scaffolds due to their large pore size structure. The obtained Young's modulus value of collagen scaffold in the presence of TES- PAMAM- $\mathrm{G}_{3}-\mathrm{ZnO}(273.14 \pm 0.2 \mathrm{MPa})$ is higher than hydroxyapatite incorporated collagen scaffold $(230 \pm 30 \mathrm{MPa})$ [48]. It has been observed that TESPAMAM $-G_{3}$ functionalized ZnO nanoparticle mediated collagen scaffold has 92 MPa higher Young's modulus than previously fabricated ZnO- TES-PAMAM-G $\mathrm{G}_{1}-$ collagen scaffold[27]. These results suggest that TES-PAMAM-G $G_{3}$ functionalized metal oxide nanoparticles improve the mechanical strength of collagen scaffold due to their smaller size, large surface area leading to increase the cross-linking density on nanoparticle surface. The above results clearly suggested that cross-linking of MO-TES-PAMAM- $G_{3}$ in collagen can effectively enhance the mechanical properties of collagen scaffolds.

\subsection{Biodegradation of MO-TES-PAMAM- $\mathrm{G}_{3}$-Collagen Scaffold}

The in vitro biodegradation profile of dendrimer cross-linked collagen scaffold as a function of degradation time is shown in Fig. 6c. The obtained results showed that all collagen-based scaffolds prepared in this work had higher biodegradation. However, in contrast to the collagen scaffold ( $98 \%$ after 30th day), the rate of weight loss was lower in the case of nanoparticle-mediated collagen scaffolds (82$90 \% \pm 0.32-2.5$ ), indicating that the degradation trend is affected by the degree of cross-linking and the existence of the cross-linker. The cross-linked scaffold initially had low weight loss (up to one week) and thereafter the scaffold underwent steady degradation indicated by a decrease in weight with time. As 
compared to the collagen scaffold, the metal oxide nanoparticle mediated collagen scaffold has a higher degree of cross-linking and is more resistance to degradation in PBS medium at $37^{\circ} \mathrm{C}$. The formation of covalent bonds between collagen and MO-TES-PAMAM-G3 NPs may be possible reason for higher scaffold strength and for a longer period of time.

\subsection{Swelling Degree of MO-TES-PAMAM-G ${ }_{3}$-Collagen Scaffold}

The swelling degree or water uptake is a significant parameter that represents the efficiency of oxygen and nutrient transfer inside the scaffold. Swelling degrees of collagen, EDC-NHS-collagen, TES-PAMAM$\mathrm{G}_{3}$-collagen, and MO-TES-PAMAM- $\mathrm{G}_{3}$-collagen scaffolds in water medium are showed in Fig. $6 \mathrm{~d}$. Generally, highly porous collagen scaffolds have a very high swelling degree, compared to less porous scaffold[49]. As shown in the figure, collagen, TES-PAMAM- ${ }_{3}$-collagen, and MO -TES-PAMAM- ${ }_{3}$ collagen scaffolds possess higher swelling capability. However, the swelling degree of the collagen scaffold was much higher than the metal oxide nanoparticle mediated collagen scaffold because of the hydrophilic properties of the carboxylic group and its porous structure, which can greatly influence the scaffold swelling degree. Among the different metal oxide nanoparticle mediated collagen scaffolds, there is no significant difference in swelling behaviour. This finding was corroborated with reports of Ullah et al. have reported that the swelling ratio of collagen was decreased in the presence of $\mathrm{ZnO}$ nanoparticle[14].This effect may be explained by the metal oxide nanoparticle interacting with the collagen fibre and serving as a filler to fill the gap space inside the scaffold network, resulting in a more compact scaffold that does not swell as much as a pure collagen scaffold.

\subsection{Quantification of Cross-linking degree between collagen and MO-TES-PAMAM- ${ }_{3}$ NPS}

The degree of cross-linking in collagen-nanoparticle interaction was quantified from a number of activated carboxylic acid groups in EDC-NHS reaction, and obtained results are shown in S5, Supplementary file. The collagen sample indicated $96 \pm 2.88 \%$ of activated carboxylic group, inferring that EDC reagent not activate $100 \%$ of the carboxylic group in collagen. The EDC cross-linked collagen sample showed that $23 \pm 2.19 \%$ of the activated carboxylic group was consumed by the cross-linking reaction. In the case of TES-PAMAM- $G_{3}$ and MO- TES-PAMAM $-G_{3}$ cross-linked collagen $66 \pm 0.90 \%, 84 \pm$ $0.36 \%, 82 \pm 0.42 \%, 84 \pm 0.36 \%, 81 \pm 0.45 \%$ and $83 \pm 0.39 \%$ of activated carboxylic acid group was consumed by cross-linking reaction for $\mathrm{ZnO}, \mathrm{TiO}_{2}, \mathrm{Fe}_{3} \mathrm{O}_{4}, \mathrm{CeO}_{2}$ and $\mathrm{SiO}_{2}$ nanoparticle respectively. This result reveals that a large number of the activated carboxylic group was consumed when MO -TESPAMAM- $\mathrm{G}_{3}$ were introduced to the EDC-NHS cross linking reaction, resulting in a higher degree of crosslinking through the carboxylic acid groups of collagen with free amine groups of dendrimer, thus leading to the improved extent of reaction.

\subsection{Cell-Viability}

To investigate the effect of concentration of MO-TES-PAMAM- $\mathrm{G}_{3}$ nanoparticle in collagen scaffold on the biological behaviour of cells, Keratinocyte was employed to assess cell viability. The cell-viability of 
collagen, EDC-NHS- collagen, TES-PAMAM-G ${ }_{3}$-collagen, and MO -TES-PAMAM-G ${ }_{3}$-collagen-based scaffolds were analyzed through MTT assay, and observed results are showed in S6, Supplementary file. As can be seen in the figure, the cell viability of collagen scaffolds was highly depended on the concentration of TES-PAMAM- $G_{3}$ and MO-TES-PAMAM- $G_{3}$. The cell viability of TES-PAMAM- $G_{3}$ crosslinked collagen scaffold decreased gradually as the concentration of TES-PAMAM- $\mathrm{G}_{3}$ increased, which was more pronounced at higher dendrimer concentrations. At higher concentrations, the cationic TESPAMAM $-G_{3}$ dendrimer may lead to cellular bonding through electrostatic attraction with negatively charged cells. Due to the high concentration of dendrimer, excessive cell bonding or severe cell membrane damage can occur, resulting in the low cell viability observed. However, up to $50 \mu \mathrm{M}$ concentration of dendrimer, cells are viable in a collagen scaffold. This observation was consistent with other reports, where in 10-100 $\mu \mathrm{M}$ PAMAM induced minimal cytotoxicity and use of $50 \mu \mathrm{M}$ of PAMAM for the crosslinking of collagen scaffold was appropriate, especially when the release of dendrimer from the scaffold was relatively slow during the biodegradation of collagen[28]. Up to $100 \mu \mathrm{M}$, the metal oxides nanoparticle cross-linked collagen scaffold showed $80 \%$ of cell viability. This observation implies that after the functionalization of TES-PAMAM-G ${ }_{3}$ on the nanoparticle surface, the cell viability was enhanced when compared to dendrimer alone.

\subsection{Wound healing study of MO-TES-PAMAM-G ${ }_{3}$ - Collagen Scaffolds}

The wound healing efficiency of the collagen-based scaffold was investigated through in vivo animal test on Wistar Albino rats. For this collagen, TES-PAMAM- $\mathrm{G}_{3}$ - collagen, and MO- TES-PAMAM- $\mathrm{G}_{3}$ - collagen scaffolds were implanted on the wounded area and wound healing efficiency monitored periodically (on days $7,14,21,28$ ) and percentage of wound closure was measured (Fig. 7a-b). For the comparison of wound healing process, saline water treated open wound was kept as a control. As seen in the figure, the groups that were treated with metal oxide nanoparticles had stronger wound healing properties than the other groups all of the time.

On day 7 , there was $62-79 \%$ wound contraction in the metal oxide nanoparticle treated groups, whereas in control, collagen, TES-PAMAM- $\mathrm{G}_{3}$ - collagen scaffold treated groups wound contraction was observed to be $28 \%, 46 \%$ and $54 \%$ respectively. On day 9 , wound contraction ( $90 \%$ ) was observed in $\mathrm{ZnO}$ mediated collagen scaffold compared to other metal oxide nanoparticles. The wound contraction was enhanced in all the groups with no sign of inflammation on day 14. In presence of metal oxide nanoparticle treated groups, the wound contraction nearly reached $71-96 \%$, while the wounds of the control and other groups were not healing well. On day 21 and 28 , the same tendency was observed with metal oxide nanoparticle treated groups. The increase in wound healing efficacy observed with metal oxide nanoparticle treated scaffolds due to their smaller size with better antibacterial activity through electrostatic interaction of positively charged metal oxide with negatively charged bacterial membrane leads to release the reactive oxygen species (ROS) on surfaces of the nanoparticles, which result in damage bacterial cell (Fig. S7S10, Supplementary file). Among the different metal oxide nanoparticle treated groups, ZnO exhibited higher wound contraction followed by $\mathrm{TiO}_{2}$ and $\mathrm{CeO}_{2}$ nanoparticle. Although, the difference in percentage 
of wound contraction between $\mathrm{Fe}_{3} \mathrm{O}_{4}$ and $\mathrm{SiO}_{2}$ nanoparticles were negligible $(\mathrm{p} \geq 0.002)$. The wound healing efficiency of metal oxide nanoparticle followed order: $\mathrm{ZnO}>\mathrm{TiO}_{2}>\mathrm{CeO}_{2}>\mathrm{Fe}_{3} \mathrm{O}_{4}>\mathrm{SiO}_{2} \mathrm{NPs} .14$ $\mathrm{nm}$ size of ZnO-TES-PAMAM- $\mathrm{G}_{3}$ mediated collagen scaffold showed large wound contraction $(90 \%)$ on day 9 , whereas previously fabricated $40-75 \mathrm{~nm}$ size of $\mathrm{ZnO}$-TES-PAMAM-G ${ }_{1}$ mediated collagen scaffold (84\%) on day 14. This accelerated wound contraction can be attributed to $14 \mathrm{~nm}$ size of $\mathrm{ZnO}-\mathrm{TES}-$ PAMAM- $G_{3}$ nanoparticle coupled with larger surface areas, which result in higher cross - linking density with collagen. This cross - linked collagen scaffold exhibited higher mechanical strength, pore size, better cell - viability and antibacterial activity leads to acceleatate wound healing process much faster than other metal oxide nanoparticle.

\subsection{Histopathology and Masson's trichrome stain study}

Furthermore, both histopathological and masson trichrome-stained wound sections were examined under the microscope to confirm the quality and maturity of the healing nature of tissue on different days. Figure 8a (10x magnification) shows $\mathrm{H}$ \& E stained sections of healing wounds from control, collagen, TES-PAMAM- $G_{3}$-collagen, MO -TES-PAMAM $-G_{3}$ - collagen treated groups on days 7,14 and 21 postwounding. On day 7 , the wound treated with TES-PAMAM- $G_{3}$-collagen, and MO -TES-PAMAM- $G_{3}-$ collagen scaffolds contained fewer inflammatory cells when compared to the collagen scaffold treated group and control. In addition to this, on day 7 sparsely grown blood vessels were formed perpendicular to the wounded area in all groups. In the case of control and collagen scaffold treated group, no reepithelialization occurred whereas TES-PAMAM- $G_{3}$-collagen and MO -TES-PAMAM- G $_{3}$ - collagen treated groups showed re-epithelialization layer in wounded area and exhibited lesser wound contraction. After 14 days, a continuous nascent epithelial layer was formed in all the groups, namely neo-epidermis. Although the nanoparticle-mediated collagen scaffold treated wound parts still had a few inflammatory cells, they also showed fibroblast and blood vessel formation, as well as collagen synthesis. As can be seen in the figure on day 14 , the wound contraction was greatly improved in all groups, in particular, ZnO nanoparticle treated group showed higher wound contraction than other groups.

On day 21st, a continuous nascent epithelial layer and some collagen fibers began to grow over the nanoparticle-mediated collagen scaffolds-treated wounds, indicating complete healing. Furthermore, histopathological images of nanoparticle-mediated collagen scaffold revealed more matured dermis and epidermis layers when compared to control groups. The non-treated group had a slower epithelialization rate and less collagen bundle development, as well as irregular collagen fibre packing. The average gap length between newly formed epithelium in TES-PAMAM- $\mathrm{G}_{3}$ - collagen scaffolds treated group was lower than collagen and control groups. On day 21, metal oxide nanoparticle treated groups showed complete wound contraction than other scaffolds, especially $\mathrm{ZnO}$ nanoparticle treated group exhibited completely closed wound. The enhanced wound healing behavior of nanoparticle-mediated collagen scaffold treated groups may be attributed to a combination of factors including a favourable bioactive environment for re-epithelialization, antimicrobial growth inhibition, fluid handling properties, and 
moisture vapour permeability of the scaffold, all of which could provide an ideal moist environment around the wound site for accelerated healing[50].

On the other hand, Masson's trichrome staining of TES-PAMAM- $\mathrm{G}_{3}$ and ZnO -TES-PAMAM- $\mathrm{G}_{3}$ treated collagen scaffolds were indicated (Fig. 8b) the formation of fair and typical collagen layer with large macrophage and fibroblast density. This observation inferring that wounds treated with ZnO-TESPAMAM-G ${ }_{3}$ NPs healed faster in comparison to all other groups due to more number of fibroblast, keratinocyte migration and collagen deposition in wound site leading to acceleration in the healing process.

\subsection{Quantification of released metal ion from scaffold - ICP-OES Analysis}

The metal ion content of TES- PAMAM- $\mathrm{G}_{3}$ functionalized MO nanoparticle mediated collagen scaffolds implanted skin is presented in Table 5, Supplementary file. The obtained results show that $\mathrm{Zn}, \mathrm{Ti}, \mathrm{Fe}, \mathrm{Ce}$ and $\mathrm{Si}$ ions were presented in the healed skin in very small quantity such as $0.12,0.10,0.91,0.06$, and $0.15 \mathrm{ppm}$. The iron oxide nanoparticle has highly leached from scaffold material when compared to other metal oxide nanoparticle. There is no significant difference noticed in terms of ion leaching between $\mathrm{ZnO}$ and $\mathrm{CeO}_{2}$ nanoparticle ( $\mathrm{p}$ value 0.001 ). It has been reported that minimum inhibition concentration (MIC) of different metal oxide nanoparticles against S.aureus and E.coli bacteria strain exhibited 0.0039$0.0312 \mathrm{mg} / \mathrm{mL}, 0.0097-0.0195 \mathrm{mg} / \mathrm{mL}, 6.25-12.5 \mathrm{mg} / \mathrm{mL}, 2.15-10.0 \mathrm{mg} / \mathrm{mL}$ and $0.0006 \mathrm{mg} / \mathrm{mL}$ for $\mathrm{ZnO}, \mathrm{TiO}_{2}$ and $\mathrm{Fe}_{3} \mathrm{O}_{4}, \mathrm{CeO}_{2}$ and $\mathrm{SiO}_{2} \mathrm{NPs}$ respectively[51-56]. The obtained concentration of leached metal ions from collagen based scaffold showed much lower than the MIC concentration of metal oxide nanoparticle. This observation clearly implies that the antibacterial activity of metal oxide nanoparticle responsible for generation of reactive oxygen species on the nanoparticle surface. In this study, ZnO-TESPAMAM $-G_{3}$ mediated collagen scaffold exhibited lesser leaching $(0.12 \mathrm{ppm})$ than previously fabricated ZnO-TES-PAMAM- $\mathrm{G}_{1}$ mediated collagen scaffold $(0.37 \mathrm{ppm})$. The decreasing the ion leaching in the case of smaller size of spherical shape of $\mathrm{ZnO}$ nanoparticle due to their higher cross- linking density leading to stronger interaction (higher cross-linking density) with collagen fiber. The obtained decrease in the quantity of metal oxide nanoparticle in comparison to added quantity could be due to the loss of particles during scaffold preparation. Further, these small quantities of nanoparticle (size $>10 \mathrm{~nm}$ ) can be clear out via liver and the mononuclear-phagocyte system (MPS)[57].

\subsection{Conclusions}

In this work, metal oxide nanoparticles ( $\mathrm{MOs}$ : $\mathrm{ZnO}, \mathrm{TiO}_{2}, \mathrm{Fe}_{3} \mathrm{O}_{4}, \mathrm{CeO}_{2}$, and $\mathrm{SiO}_{2}$ ) with sphere shape were synthesized through co-precipitation method. The synthesized nanoparticle surface was modified with TES-PAMAM- $\mathrm{G}_{3}$ dendrimer and well characterized. The TES-PAMAM- $\mathrm{G}_{3}$ dendrimer coated metal oxide nanoparticles were assimilated in the self-assembly processes of collagen, leading to MO-TES-PAMAM$\mathrm{G}_{3}$-collagen scaffolds. The in-vitro cell viability of metal oxide nanoparticle mediated collagen scaffolds were analysed through MTT assay, and their in-vivo skin regeneration efficiency was executed on Wistar 
Albino rats. Our results suggested that the $14 \mathrm{~nm}$ size of ZnO-TES-PAMAM-G ${ }_{3}$ nanoparticle-mediated collagen scaffold exhibited higher pore size, mechanical strength, controlled biodegradation, better antibacterial activity and cell - viability leading to an acceleration of the re-epithelization process on wound site and thereby promote wound healing without scar formation.

\section{Declarations}

\section{Acknowledgment}

We sincerely thank Department of Biotechnology (DBT), Government of India for providing the funds to carry out this research work (Grant Number-BT/PR9867/NNT/28/696/2013).MV is also thanking to CSIR for providing financial support in form of Research Associate fellowship (Grant Number: 31/0006 (11129)/2021-EMR-I). In addition, we thank to Dr. U Mani and B Ram Kumar for their kind support during in vivo animal work. CSIR-CLRI communication number: 1549

\section{Ethical Approval: Not applicable}

Consent to participate: Not applicable

Consent to publish: Not applicable

\section{Author contributions}

Dr MV has performed the research work and wrote the manuscript. Dr ASK has carried out the antibacterial activity, ROS detection and lipid peroxidation studies. Dr KJS, Dr ASK and Dr BUN were discussed the results and improved the entire manuscript. All authors have approved the final version of the manuscript.

\section{Competing Interests:}

The authors declare that they have no known competing financial interests or personal relationship that could have appeared to influence the work reported in this paper.

\section{Availability of data and materials:}

The authors confirm that the data analysed and generated from these research finding are provided within this article.

\section{References}

1. Zhao, X., Guo, B., Wu, H., Liang, Y., \& Ma, P. X. (2018). Injectable antibacterial conductive nanocomposite cryogels with rapid shape recovery for noncompressible hemorrhage and wound healing. Nat. commun, 9(1), 1-17) 
2. Feng, Y., Wang, Q., He, M., Zhao, W., Liu, X., \& Zhao, C., (2019), Nonadherent Zwitterionic Composite Nanofibrous Membrane with a Halloysite Nanocarrier for Sustained Wound Anti-Infection and Cutaneous Regeneration.ACS Biomater. Sci. Eng.6(1),621-633.

3. Liang, Y., Zhao, X., Hu, T., Chen, B., Yin, Z., Ma, P. X., \& Guo, B., (2019), Adhesive hemostatic conducting injectable composite hydrogels with sustained drug release and photothermal antibacterial activity to promote full-thickness skin regeneration during wound healing.Small, 15 (12), 1900046.

4. Qu, J., Zhao, X., Liang, Y., Xu, Y., Ma, P. X., \& Guo, B. (2019). Degradable conductive injectable hydrogels as novel antibacterial, anti-oxidant wound dressings for wound healing. Chem. Eng. J. (Amsterdam,Neth, 362, 548-560)

5. Zhao, X., Wu, H., Guo, B., Dong, R., Qiu, Y., \& Ma, P. X. (2017). Antibacterial anti-oxidant electroactive injectable hydrogel as self-healing wound dressing with hemostasis and adhesiveness for cutaneous wound healing. Biomaterials, 122, 34-47)

6. Chattopadhyay, S., \& Raines, R. T. (2014). Collagen-based biomaterials for wound healing. Biopolymers, 101(8), 821-833

7. Brett, D., (2008), A review of collagen and collagen-based wound dressings. Wounds, 20 (12),347356.

8. Miranda-Nieves, D., \& Chaikof, E. L., (2017), Collagen and elastin biomaterials for the fabrication of engineered living tissues.ACS Biomater. Sci. Eng., 3 (5),694-711.

9. Vedhanayagam, M., Nair, B. U., \& Sreeram, K. J., (2019), Dimension effect: Dendrimer functionalized carbon based nanomaterial mediated collagen scaffold for wound healing application.Materialia, 7,100354 .

10. Grant, S. A., Spradling, C. S., Grant, D. N., Fox, D. B., Jimenez, L., Grant, D. A., \& Rone, R. J., (2014), Assessment of the biocompatibility and stability of a gold nanoparticle collagen bioscaffold.J.Biomed. Mater. Res. A, 102 (2),332-339.

11. Akturk, O., Kismet, K., Yasti, A. C., Kuru, S., Duymus, M. E., Kaya, F. ... Keskin, D., (2016), Collagen/gold nanoparticle nanocomposites: a potential skin wound healing biomaterial.J.Biomater. Appl., 31 (2),283-301.

12. Vedhanayagam, M., Nidhin, M., Duraipandy, N., Naresh, N. D., Jaganathan, G., Ranganathan, M. ... Sreeram, K. J., (2017), Role of nanoparticle size in self-assemble processes of collagen for tissue engineering application. Int. J.Biol. Macromol.99,655-664.

13. Nidhin, M., Vedhanayagam, M., Sangeetha, S., Kiran, M. S., Nazeer, S. S., Jayasree, R. S. ... Nair, B. U. (2014). Fluorescent nanonetworks: A novel bioalley for collagen scaffolds and Tissue Engineering. Sci. Rep, 4(1), 1-10)

14. Ullah, S., Zainol, I., \& Idrus, R. H., (2017), Incorporation of zinc oxide nanoparticles into chitosancollagen 3D porous scaffolds: Effect on morphology, mechanical properties and cytocompatibility of 3D porous scaffolds. Int. J.Biol. Macromol., 104,1020-1029. 
15. Kwan, K. H. L., Liu, X., To, M. K. T., Yeung, K. W. K., Ho, C., \& Wong, K. K. Y., (2011), Modulation of collagen alignment by silver nanoparticles results in better mechanical properties in wound healing.Nanomedicine (N.Y., N.Y., U.S.), 7(4),497-504.

16. Mertens, M. E., Hermann, A., Bühren, A., Olde-Damink, L., Möckel, D., Gremse, F. ... Lammers, T., (2014), Iron oxide-labeled collagen scaffolds for non-invasive MR imaging in tissue engineering.Adv. Funct. Mater., $24(6), 754-762$.

17. Mohandas, A., Deepthi, S., Biswas, R., \& Jayakumar, R., (2018), Chitosan based metallic nanocomposite scaffolds as antimicrobial wound dressings.Bioact. Mater., 3 (3),267-277.

18. Mandoli, C., Pagliari, F., Pagliari, S., Forte, G., Di Nardo, P., Licoccia, S., \& Traversa, E., (2010), Stem cell aligned growth induced by $\mathrm{CeO} 2$ nanoparticles in PLGA scaffolds with improved bioactivity for regenerative medicine.Adv. Funct. Mater.,20 (10),1617-1624.

19. Castaneda, L., Valle, J., Yang, N., Pluskat, S., \& Slowinska, K., (2008), Collagen cross-linking with Au nanoparticles. Biomacromolecules, 9 (12),3383-3388.

20. Laurenti, M., \& Cauda, V., (2017), ZnO nanostructures for tissue engineering applications. Nanomaterials,7(11), 374.Doi.org/10.3390/nano7110374

21. Hao, S., Zhang, Y., Meng, J., Liu, J., Wen, T., Gu, N., \& Xu, H., (2018), Integration of a superparamagnetic scaffold and magnetic field to enhance the wound-healing phenotype of fibroblasts.ACS Appl. Mater. \& Interfaces, 10 (27),22913-22923.

22. Huang, X., Li, L. D., Lyu, G. M., Shen, B. Y., Han, Y. F., Shi, J. L. ... Wu, J. H., (2018), Chitosan-coated cerium oxide nanocubes accelerate cutaneous wound healing by curtailing persistent inflammation.Inorg. Chem. Front.,5(2),386-393.

23. Matter, M. T., Starsich, F., Galli, M., Hilber, M., Schlegel, A. A., Bertazzo, S. ... Herrmann, I. K., (2017), Developing a tissue glue by engineering the adhesive and hemostatic properties of metal oxide nanoparticles. Nanoscale, 9 (24),8418-8426.

24. Balaure, P. C., Holban, A. M., Grumezescu, A. M., Mogoşanu, G. D., Bălşeanu, T. A., Stan, M. S. ... Mogoantă, L., (2019), In vitro and in vivo studies of novel fabricated bioactive dressings based on collagen and zinc oxide 3D scaffolds.Int. J. Pharm. (Amsterdam,Neth.),557,199-207.

25. Ghosal, K., Thomas, S., Kalarikkal, N., \& Gnanamani, A., (2014), Collagen coated electrospun polycaprolactone (PCL) with titanium dioxide (TiO 2) from an environmentally benign solvent: Preliminary physico-chemical studies for skin substitute.J.Polym. Res.,21 (5), 410.Doi.org/10.1007/s10965-014-0410-y

26. Li, N., Fan, X., Tang, K., Zheng, X., Liu, J., \& Wang, B., (2016), Nanocomposite scaffold with enhanced stability by hydrogen bonds between collagen, polyvinyl pyrrolidone and titanium dioxide.Colloids Surf., B, 140,287-296.

27. Vedhanayagam, M., Unni Nair, B., \& Sreeram, K. J. (2018). ), Collagen-ZnO scaffolds for wound healing applications: role of dendrimer functionalization and nanoparticle morphology. ACS Appl. Bio Mater, 1(6), 1942-1958( 
28. Zhong, S., \& Yung, L. Y. L., (2009), Enhanced biological stability of collagen with incorporation of PAMAM dendrimer.J. Biomed. Mater. Res. A, 91 (1),114-122.

29. Duan, X., \& Sheardown, H., (2005), Crosslinking of collagen with dendrimers.J. Biomed. Mater. Res. A, $75(3), 510-518$.

30. Vrana, N. E., Builles, N., Kocak, H., Gulay, P., Justin, V., Malbouyres, M. ... Hasirci, V., (2007), EDC/NHS cross-linked collagen foams as scaffolds for artificial corneal stroma.J. Biomater.Sci., Polym. Ed.18 (12), 1527-1545.

31. Chandrakasan, G., Torchia, D. A., \& Piez, K. A., (1976), Preparation of intact monomeric collagen from rat tail tendon and skin and the structure of the nonhelical ends in solution.J.Biol. Chem.251 (19),6062-6067.

32. Rajan, N., Habermehl, J., Coté, M. F., Doillon, C. J., \& Mantovani, D., (2006), Preparation of ready-touse, storable and reconstituted type I collagen from rat tail tendon for tissue engineering applications. Nat. Protoc., 1 (6),2753.

33. Bronstein, L. M., Huang, X., Retrum, J., Schmucker, A., Pink, M., Stein, B. D., \& Dragnea, B., (2007), Influence of iron oleate complex structure on iron oxide nanoparticle formation.Chem. Mater., 19 (15),3624-3632.

34. Wetterskog, E., Agthe, M., Mayence, A., Grins, J., Wang, D., Rana, S. ... Bergström, L., (2014), Precise control over shape and size of iron oxide nanocrystals suitable for assembly into ordered particle arrays.Sci. Technol. Adv. Mater., 15 (5),055010.

35. Williams, B. R., Gelman, R. A., Poppke, D. C., \& Piez, K. A., (1978), Collagen fibril formation.J. Biol. Chem., 253 (18),6578-6585.

36. Mosmann, T., (1983), Rapid colorimetric assay for cellular growth and survival: application to proliferation and cytotoxicity assays. J. Immunol. Methods, 65(1-2),55-63.

37. Lu, H., Ju, H., Yang, Q., Li, Z., Ren, H., Xin, X., \& Xu, G., (2013), Synthesis of Ag@ SiO 2 hybrid nanoparticles templated by a Triton X-100)/1-hexanol/cyclohexane/H 20 water-in-oil microemulsion.CrystEngComm, 15(33),6511-6517.

38. Bindu, P., \& Thomas, S., (2014), Estimation of lattice strain in ZnO nanoparticles: X-ray peak profile analysis.J.Theor. Appl. Phys., 8(4),123-134.

39. Hosseinzadeh, L., Baedi, J., \& Zak, A. K., (2014), X-ray peak broadening analysis of Fe $50 \mathrm{Ni} 50$ nanocrystalline alloys prepared under different milling times and BPR using size strain plot (SSP) method.Bull. Mater. Sci.,37(5),1147-1152.

40. Ravichandran, R., Islam, M. M., Alarcon, E. I., Samanta, A., Wang, S., Lundström, P. ... Phopase, J., (2015), Functionalised type-I collagen as a hydrogel building block for bio-orthogonal tissue engineering applications.J.Mater. Chem. B, 4(2),318-326.

41. Lopes, J. L. S., Miles, A. J., Whitmore, L., \& Wallace, B. A., (2014), Distinct circular dichroism spectroscopic signatures of polyproline II and unordered secondary structures: applications in secondary structure analyses.Protein Sci.23 (12),1765-1772. 
42. Roach, P., Farrar, D., \& Perry, C. C., (2006), Surface Tailoring for Controlled Protein Adsorption: Effect of Topography at the Nanometer Scale and Chemistry.J.Am. Chem.Soc.128 (12),3939-3945. DOI: $10.1021 / \mathrm{ja} 056278 \mathrm{e}$.

43. Park, S. J. (2020). ), Protein-Nanoparticle Interaction: Corona Formation and Conformational Changes in Proteins on Nanoparticles. Int.J.Nanomedicine. 15, 5783.Doi.org/10.2147/IJN.S254808(

44. Walczyk, D., Bombelli, F. B., Monopoli, M. P., Lynch, I., \& Dawson, K. A., (2010), What the cell "sees" in bionanoscience.J. Am. Chem. Soc., 132 (16),5761-5768.

45. Wilson, C. G., Sisco, P. N., Gadala-Maria, F. A., Murphy, C. J., \& Goldsmith, E. C., (2009), Polyelectrolytecoated gold nanorods and their interactions with type I collagen. Biomaterials,30 (29),5639-5648.

46. Hamdan, S., Pastar, I., Drakulich, S., Dikici, E., Tomic-Canic, M., Deo, S., \& Daunert, S., (2017), Nanotechnology-driven therapeutic interventions in wound healing: potential uses and applications.ACS Cent. Sci., 3 (3),163-175.

47. Jithendra, P., Rajam, A. M., Kalaivani, T., Mandal, A. B., \& Rose, C., (2013), Preparation and characterization of aloe vera blended collagen-chitosan composite scaffold for tissue engineering applications.ACS Appl.Mater.Interfaces, 5(15),7291-7298.

48. Thomas, V., Dean, D. R., Jose, M. V., Mathew, B., Chowdhury, S., \& Vohra, Y. K. (2007). Nanostructured biocomposite scaffolds based on collagen coelectrospun with nanohydroxyapatite. Biomacromolecules, 8(2), 631-637)

49. Wu, L., Li, H., Li, S., Li, X., Yuan, X., Li, X., \& Zhang, Y., (2010), Composite fibrous membranes of PLGA and chitosan prepared by coelectrospinning and coaxial electrospinning.J.Biomed. Mater.Res. A,92 (2),563-574.

50. Ohira, T., \& Yamamoto, O., (2012), Correlation between antibacterial activity and crystallite size on ceramics.Chem. Eng. Sci.,68 (1),355-361.

51. Alekish, M., Ismail, Z. B., Albiss, B., \& Nawasrah, S., (2018), In vitro antibacterial effects of zinc oxide nanoparticles on multiple drug-resistant strains of Staphylococcus aureus and Escherichia coli: An alternative approach for antibacterial therapy of mastitis in sheep. Vet.World,11 (10), 1428-1432.

52. Pişkin, S., Arzu, P., \& MÜGe, S. Y. In (2013), Antimicrobial activity of synthesized TiO2 nanoparticles, 1213004. Doi. org/10.15242/IIE 2013

53. Seifi Mansour, S., Ezzatzadeh, E., \& Safarkar, R., (2019), In vitro evaluation of its antimicrobial effect of the synthesized Fe304 nanoparticles using Persea Americana extract as a green approach on two standard strains.Asian J.Green Chem., 3 (3),353-365.

54. Pop, O. L., Mesaros, A., Vodnar, D. C., Suharoschi, R., Tăbăran, F., Magerușan, L. ... Ciontea, L., (2020), Cerium Oxide Nanoparticles and Their Efficient Antibacterial Application In Vitro against GramPositive and Gram-Negative Pathogens.Nanomaterials, 10 (8),1614. Doi:10.3390/nano10081614

55. Mathelié-Guinlet, M., Grauby-Heywang, C., Martin, A., Février, H., Morote, F., Vilquin, A. ... CohenBouhacina, T., (2018), Detrimental impact of silica nanoparticles on the nanomechanical properties of Escherichia coli, studied by AFM.J. Colloid Interface Sci., 529,53-64. 
56. Kadhum, S. A., (2017), The Effect of two Types of Nano-Particles ( $\mathrm{ZnO}$ and SiO2) on Different Types of Bacterial Growth.Biomed. Pharmacol.J., 10 (4), 1701.Doi.org/10.13005/bpj/1282

57. Bobo, D., Robinson, K. J., Islam, J., Thurecht, K. J., \& Corrie, S. R., (2016), Nanoparticle-based medicines: a review of FDA-approved materials and clinical trials to date.Pharm. Res.,33 (10),23732387.

Figures

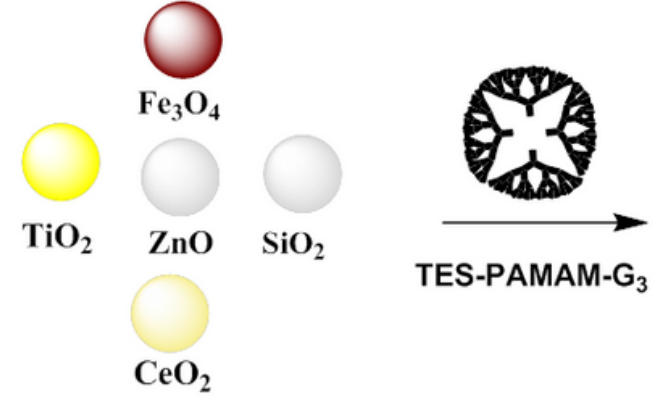

Metal Oxide (MO NPs)

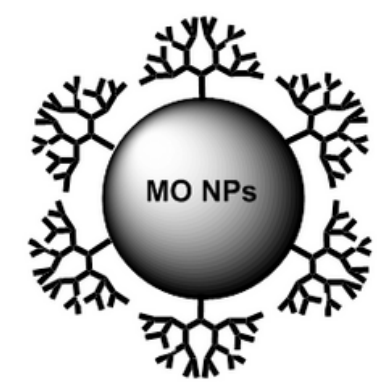

MOS- TES-PAMAM-G ${ }_{3}$ NPS

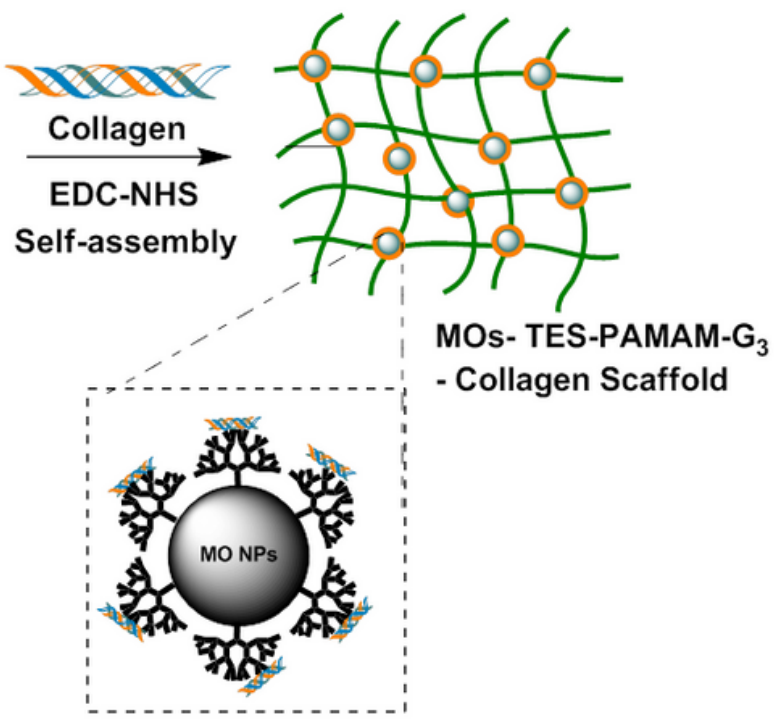

Figure 1

Schematic diagram of the construction of MOs- TES-PAMAM-G3 - collagen scaffold 


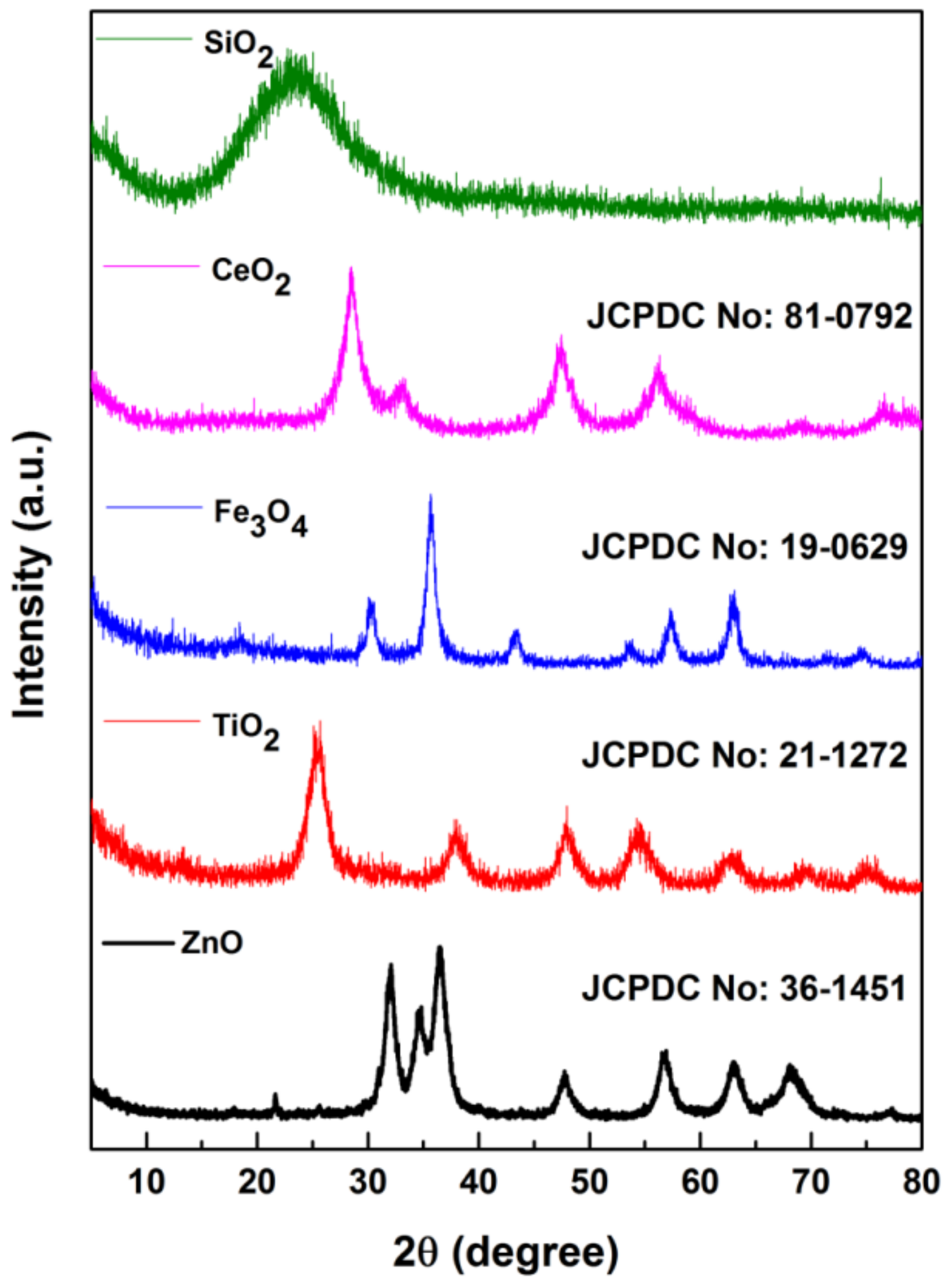

Figure 2

XRD pattern of $\mathrm{ZnO}, \mathrm{TiO} 2, \mathrm{Fe} 3 \mathrm{O} 4, \mathrm{CeO} 2$, and $\mathrm{SiO} 2$ nanoparticles 

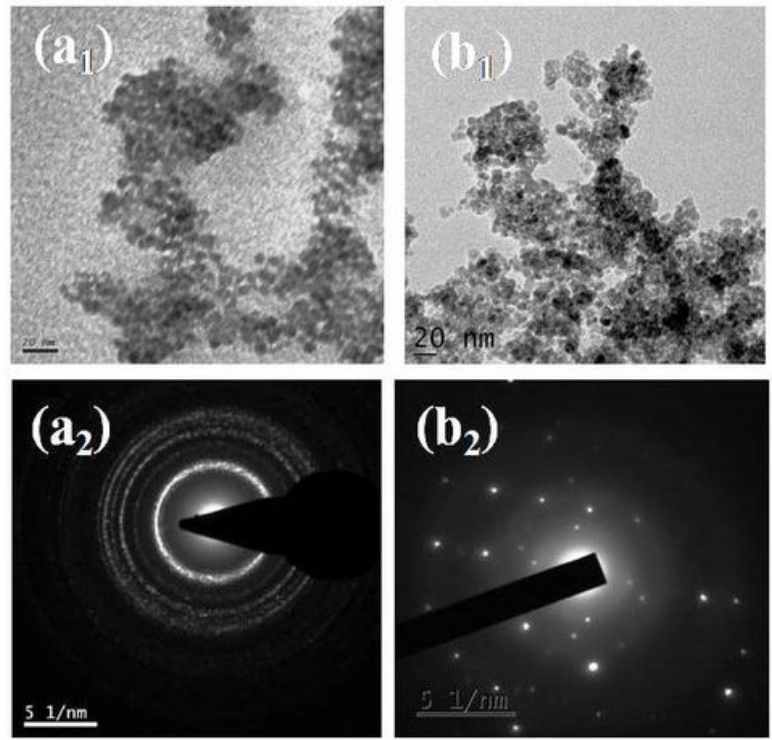

$20 \mathrm{~nm}$ (n)
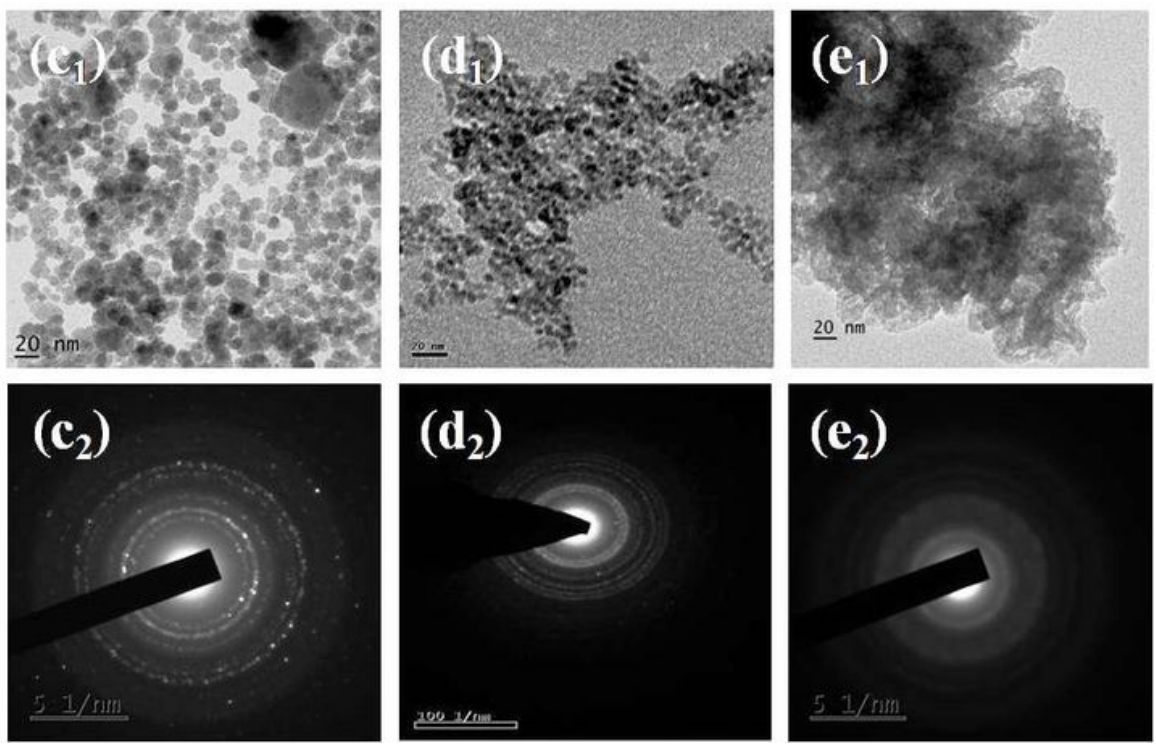

\section{Figure 3}

The TEM image of different types of metal oxide nanoparticles (Scale bar $20 \mathrm{~nm}$ ) 


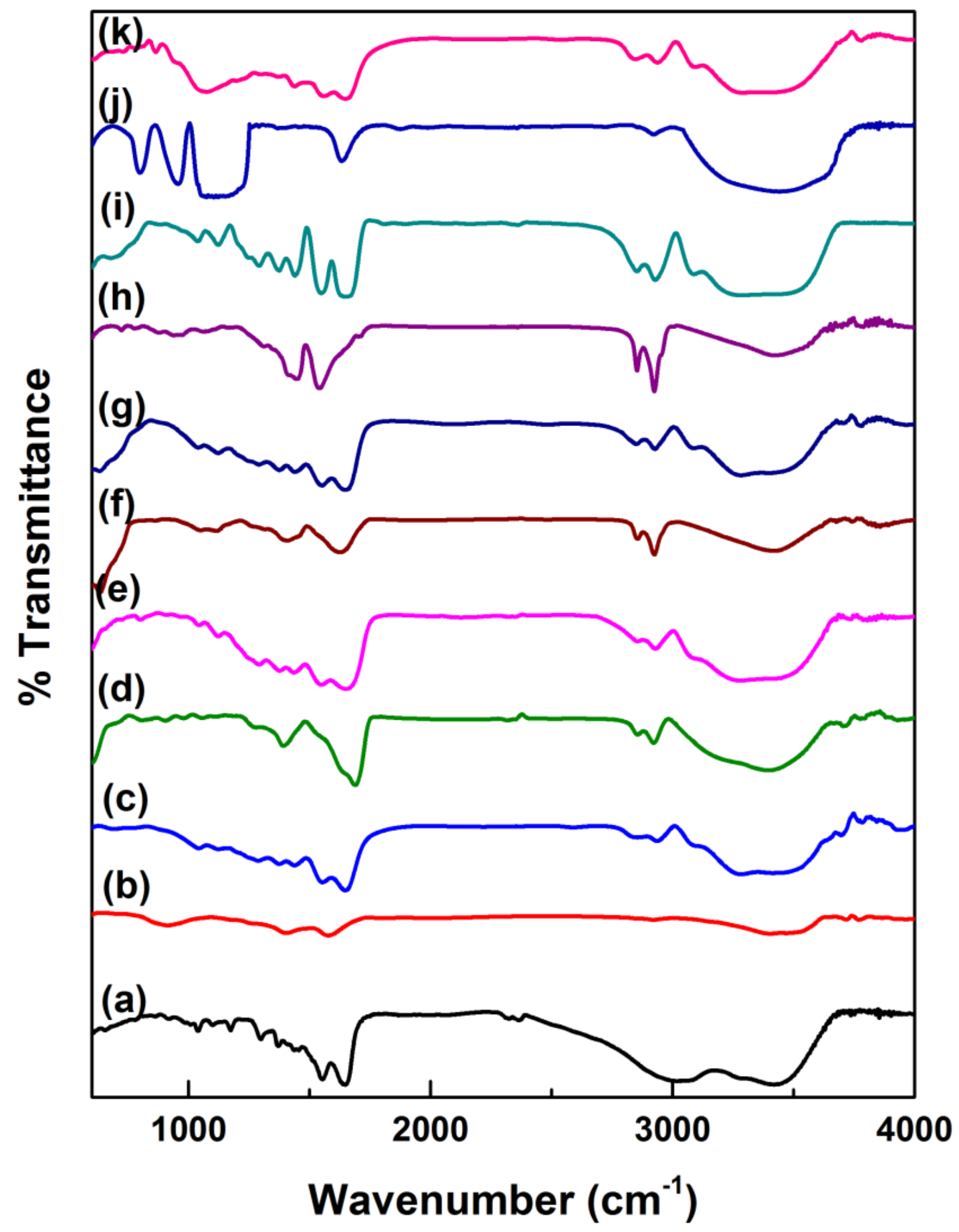

Figure 4

The FTIR spectrum of a)TES-PAMAM-G3 dendrimer and dendrimer functionalized with / without different metal oxides nanoparticles such as b) ZnO c) ZnO-TES-PAMAM-G3 d) TiO2 e) TiO2-TES-PAMAM-G3 f) Fe3O4 g) Fe304-TES-PAMAM-G3 h) CeO2 i) CeO2-TES-PAMAM-G3 j) SiO2 k) SiO2-TES-PAMAM-G3 

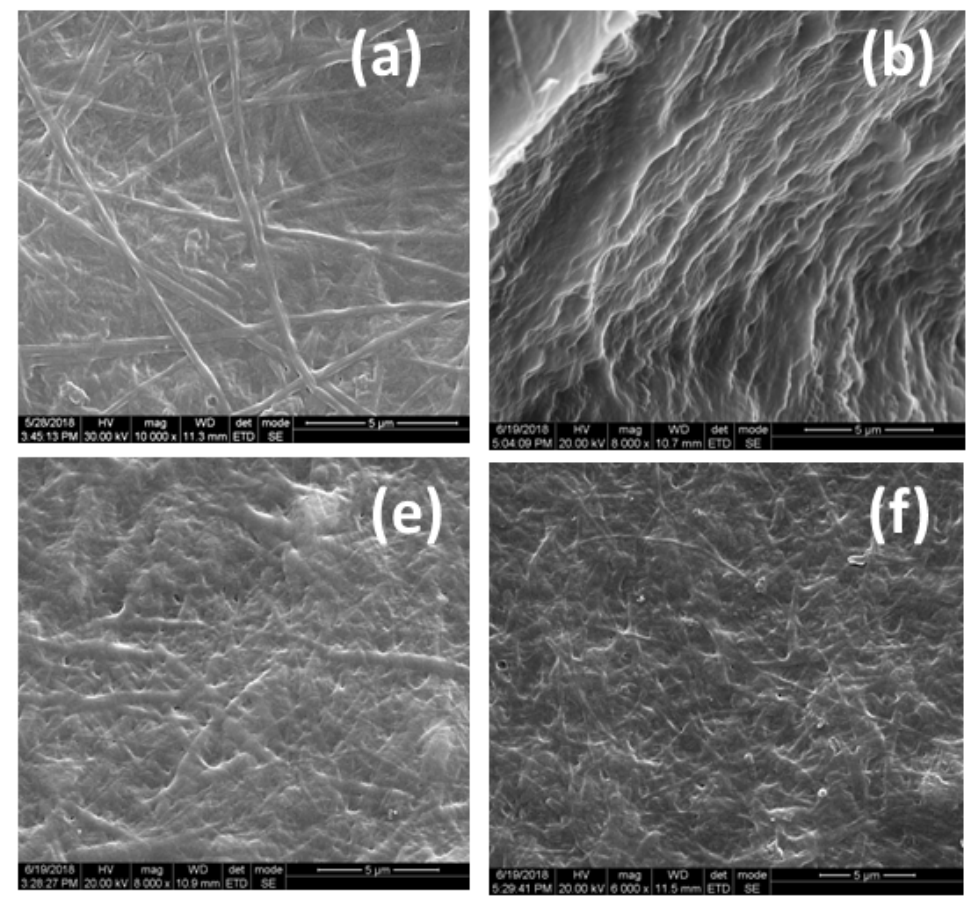
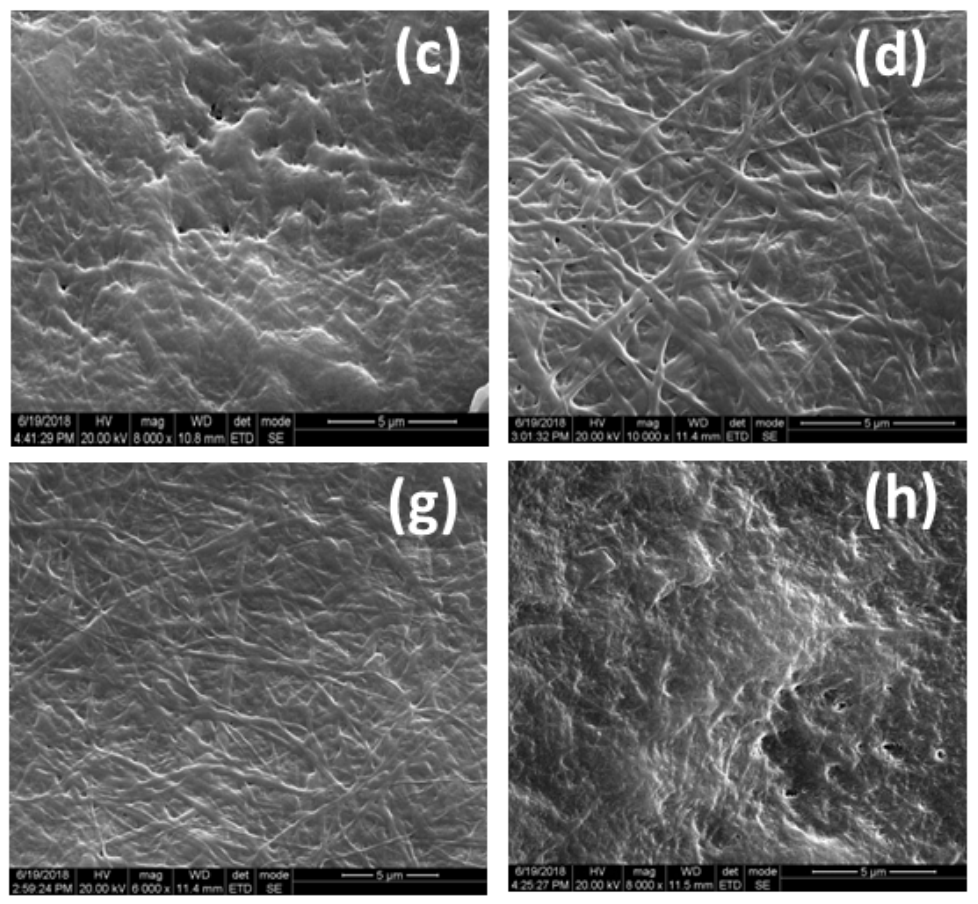

\section{Figure 5}

Morphology of different collagen scaffold such as a) collagen, b) collagen-EDC-NHS, c) TES-PAMAM -G3collagen, d) ZnO -TES-PAMAM -G3-collagene) TiO2-TES-PAMAM -G3-collagenf) Fe304-TES-PAMAM -G3collagen g) CeO2-TES-PAMAM -G3-collagen and h) SiO2-TES-PAMAM -G3- collagen scaffolds 

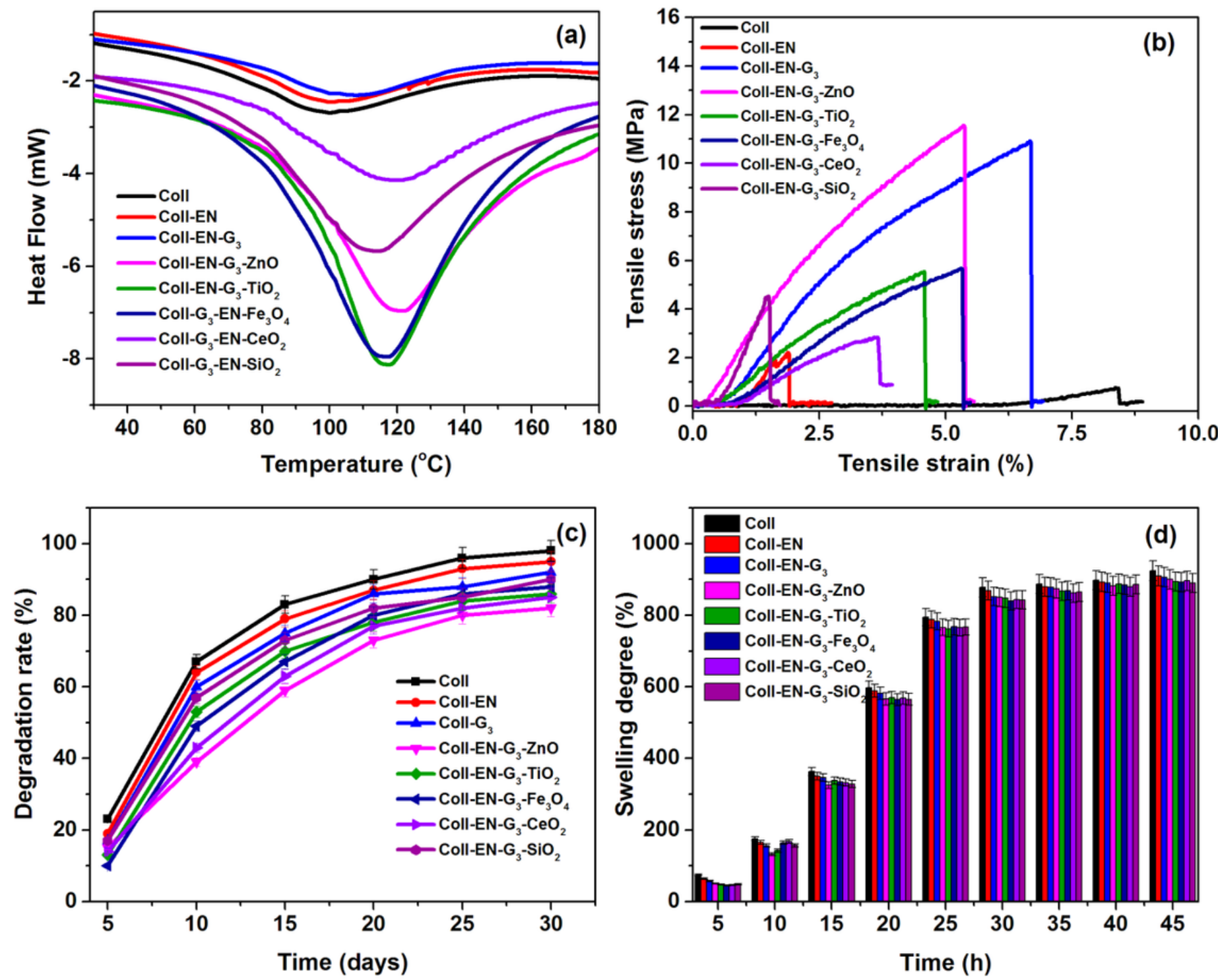

Figure 6

a) Differential scanning calorimetry b)Mechanical strength c) Bio-degradability and d) Swelling degree of collagen-based scaffolds 
(a)

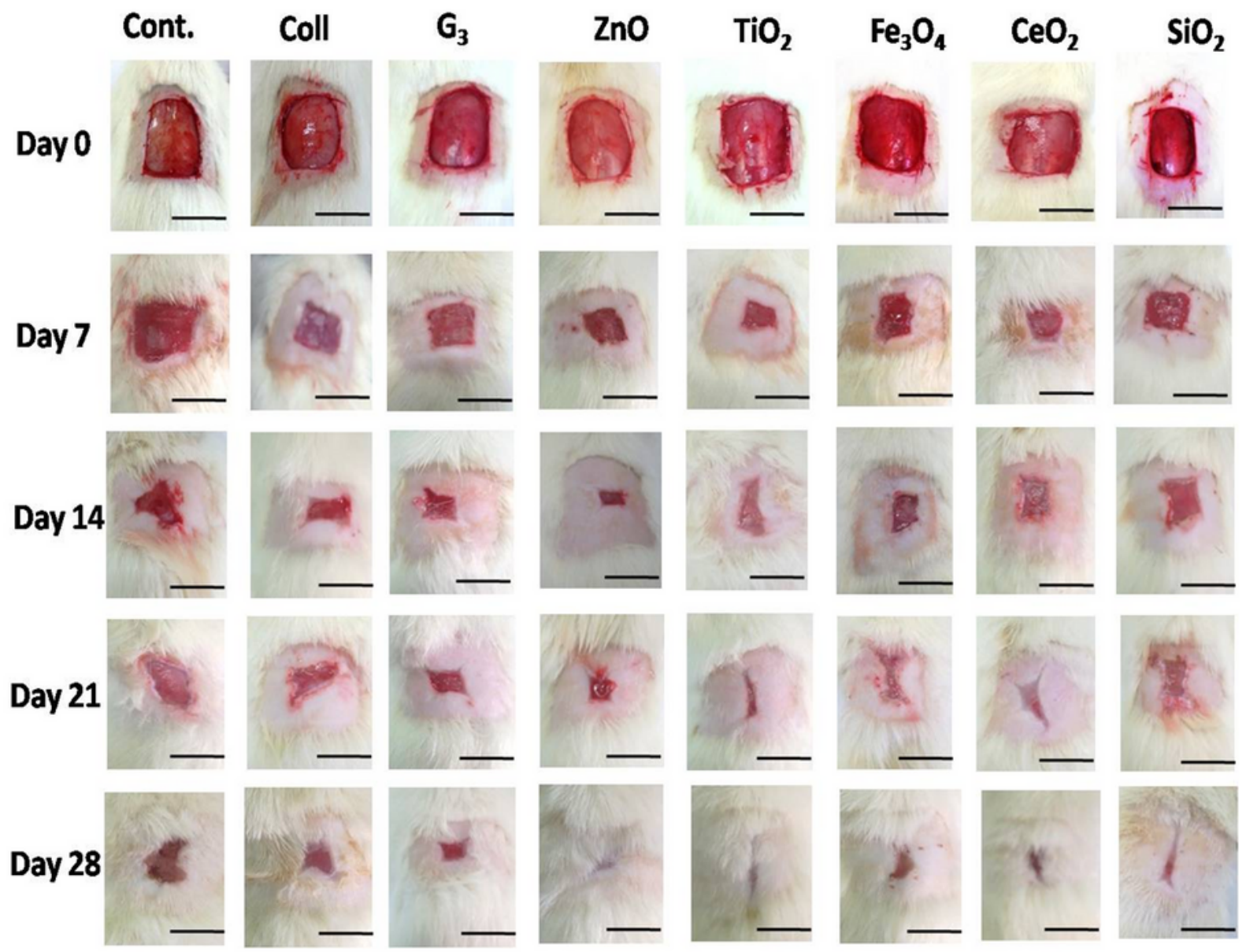

(b)

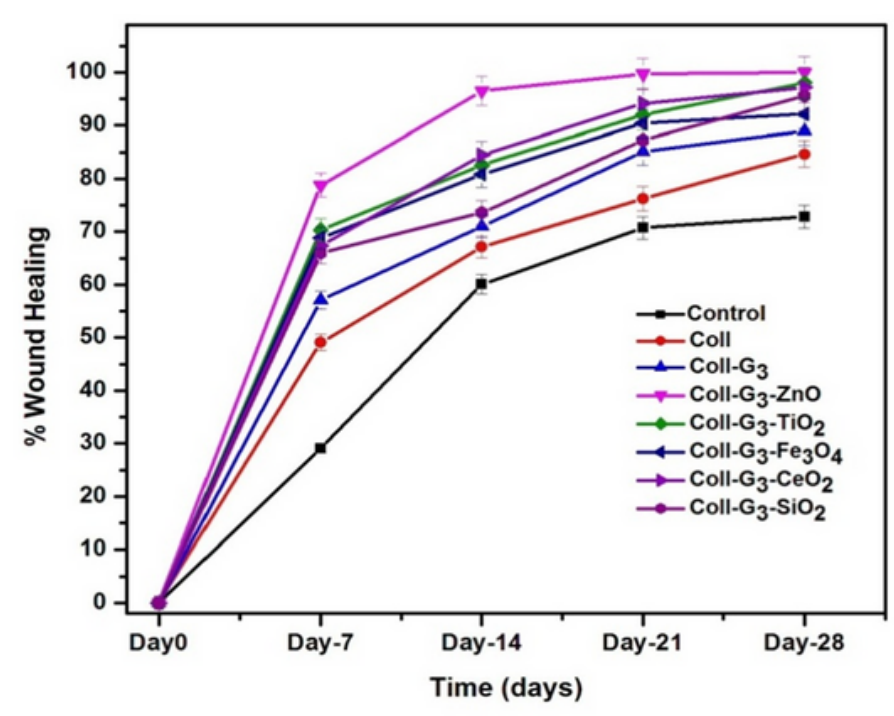

Figure 7

(a-b) a) Representative photographs of excisional wounds on Wistar albino rats at different time intervals following treatment with $\mathrm{ZnO}, \mathrm{TiO} 2, \mathrm{Fe} 3 \mathrm{O} 4, \mathrm{CeO} 2$, and $\mathrm{SiO} 2$. Scale bar: $5 \mathrm{~mm}$ b) Percentage of wound closure of metal oxide nanoparticle cross-linked collagen scaffold such as $\mathrm{ZnO}, \mathrm{TiO} 2, \mathrm{Fe} 3 \mathrm{O} 4, \mathrm{CeO}$, and SiO2incorporatedgroups on day 7, 14, 21 and 28. 
(a)
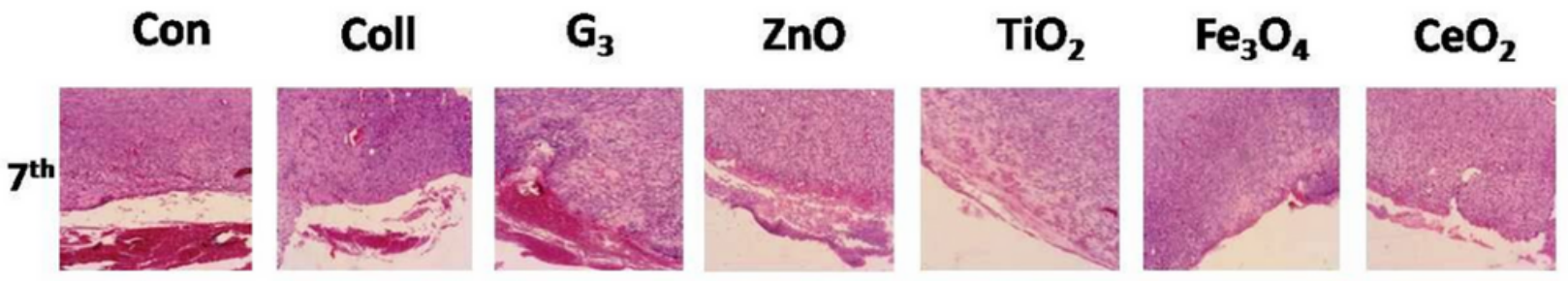

$\mathrm{SiO}_{2}$
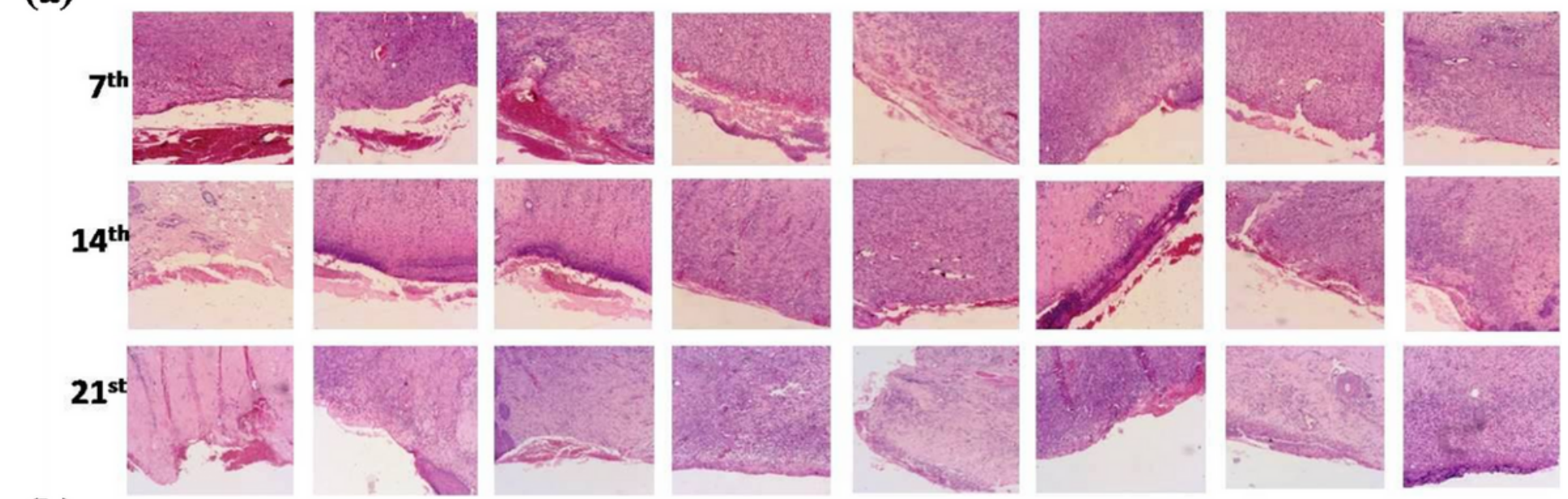

(b)
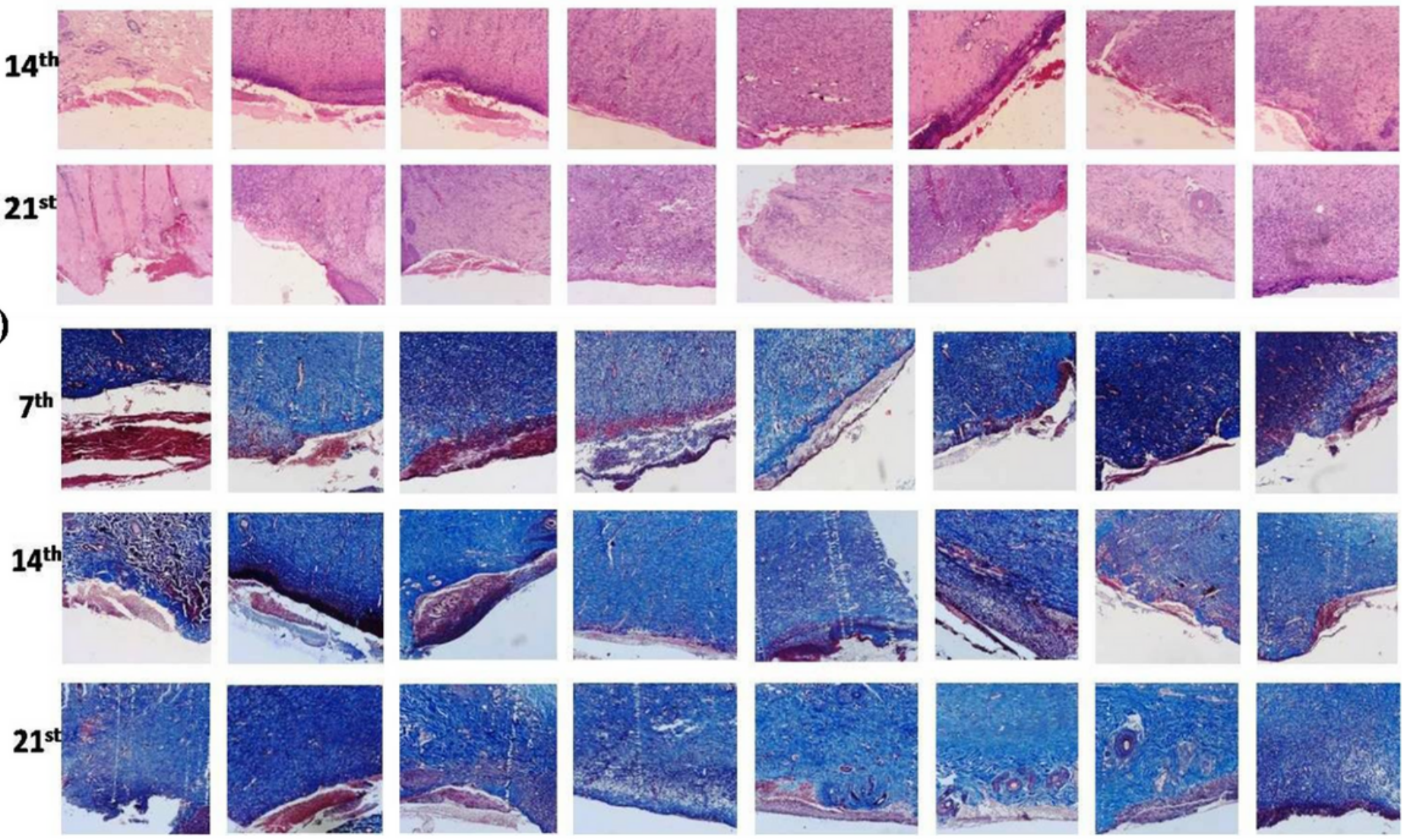

\section{Figure 8}

(a-b) a) H\&E b) Masson trichrome staining of sections of day 7, 14 and 21 of wounded tissue. The characteristics of the wound healing process with time are highlighted. Scale Bar $10 \mathrm{~m}$ (Note: Con. is the control group)

\section{Supplementary Files}

This is a list of supplementary files associated with this preprint. Click to download.

- GA.png

- SupplementaryFile.docx 